\title{
The Oxus Civilization
}

\section{La Civilización del Oxus}

\author{
C.C. Lamberg-Karlovsky
}

Recibido: 01-07-2013

Aceptado: 20-10-2013

\section{Resumen}

La Civilización del Oxus, también conocida como la Civilización de Bactria-Margiana, está centrada en el oasis de Murghab, Turkmenistán, y datada entre el 2200-1700 AC. Descubierta por Victor Sarianidi en la década de 1970, continua sus excavaciones en el poblado de +20 hectáreas de Gonur depe. La Civilización del Oxus tiene una arquitectura única, una cultura material excepcionalmente rica, y contactos con Mesopotamia, el Valle del Indo y la llanura iraní.

Palabras clave: Civilización del Oxus, Bronce Inicial, Turkmenistán, Gonur depe.

\section{Abstract}

The Oxus Civilization, also known as the Bactrian-Margina Civilization, is centere in the Murghab Oasis, Turkmenistan, and dated to 2200-1700 BC. Discovered by Victor Sarianidi in the 1970s, he continues his excavations on the +20 hectare site of Gonur depe. The Oxus Civilization has unique architecture, an exceptionally rich material culture, and contacts with Mesopotamia, the Indus Valley and the Iranian Plateau.

Key words: Oxus Civilization, Early Bronze Age, Turkmenistan, Gonur depe.

The discovery of a spectacular artifact, a rich tomb, a treasured hoard, or an ancient city belonging to the earliest civilizations attracts a very considerable attention. Thus, one might imagine that the discovery of a completely unknown civilization would create a flurry of interest. At the very least, one might expect such a discovery to attend the interest of the professional archaeologist. Not entirely so. In notable introductory texts on archaeology there is hardly mention of its existence (Fagan, 2009; Renfrew and Bahn, 2008; Scarre, 2009; Chazan 2010). In the late 1970s a remarkable archaeological complex, fully worthy of civi-

\footnotetext{
1 Stephen Phillips Professor of Archaeology and Ethnology,
} Department of Anthropology, Peabody Museum, Harvard lizational status, was uncovered in Central Asia (Sarianidi, 1976). Its principal discoverer was Victor Sarianidi, then of Moscow's Institute of Archaeology, Soviet Academy of Sciences (Fig. 1). He has spent the past 40 years excavating the $40+$ hectare site of Gonur depe in Turkmenistan. For this archaeological discovery he coined the cumbersome term the 'Bactrian Margiana Archaeological Complex', hereafter the BMAC. Bactria and Margiana were the geographical terms by which the Greeks, following Alexander's conquests referred to this region, of Central Asia. Margiana (Margush), in turn was a Persian satrapy compromising both regions.

University, 11 Divinity Avenue, Cambridge, MA 021382019, USA.karlovsk@fas.harvard.edu 


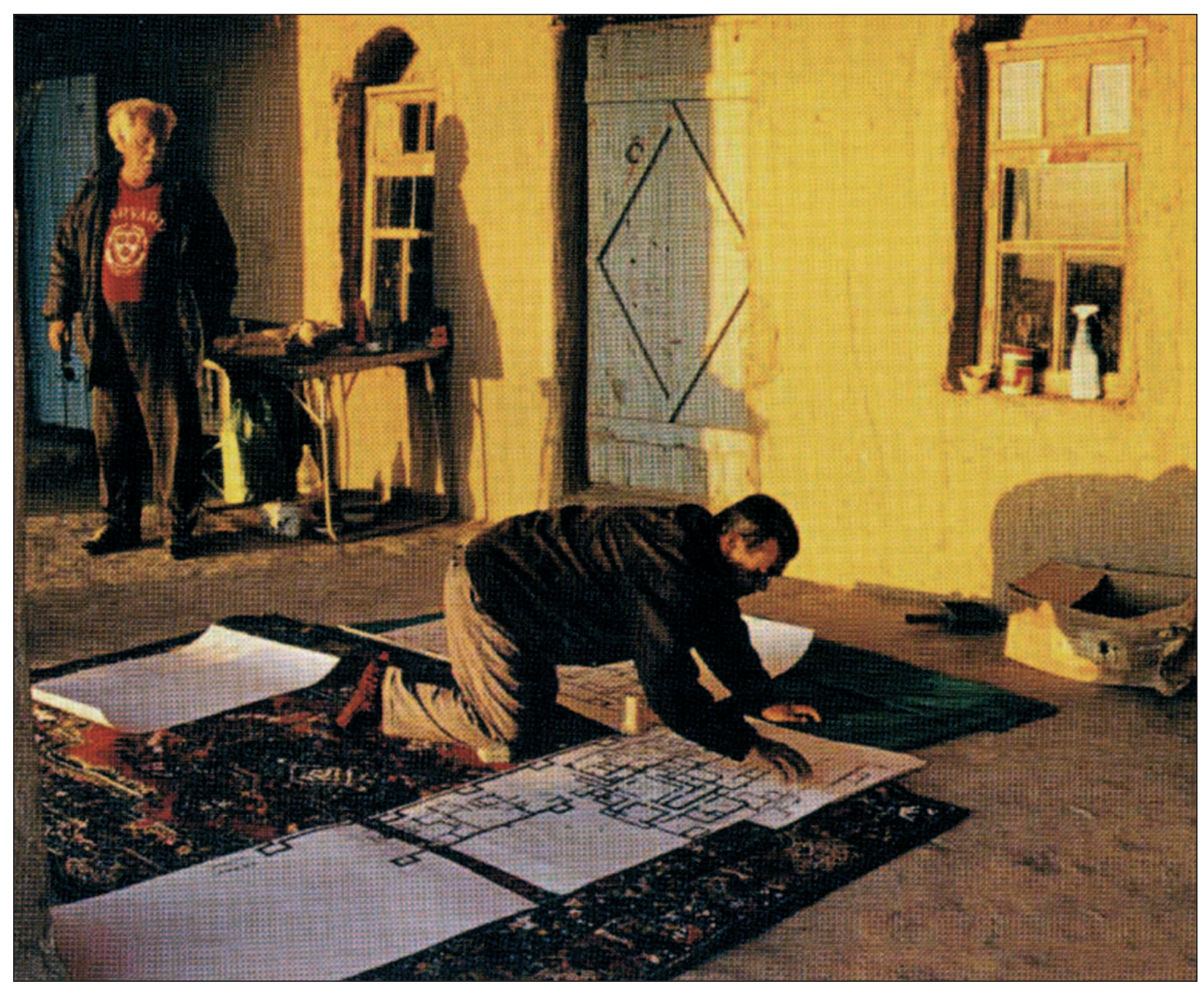

Figure 1. Victor Sarianidi in the laboratory at Gonur depe (Sarianidi, 2007: 11).

Alternatively, and with increasing frequency, the 'Oxus Civilization', is used to denote the BMAC. The Oxus being the name the Greeks used in denoting the great Amu Darya River, the greatest of Central Asian rivers. The settlement density of the BMAC is distributed along the smaller Murghab River which originates in the Paropamisus Mountains of Afghanistan and debauches into the Karakorum desert (Masimov, 1975; Salvatori, 2008). Over the past two decades this region has been subject to intensive settlement survey (Salvatori and Tosi, eds., 2008; Gubaev et alii, 1998) and the excavation of at least a half dozen sites. To date several books have been written by Victor Sarianidi (see bibliography and Lamberg-Karlovsky, 2003 for review), largely based on his own excavations at the site of Gonur depe. His books are published in Turkmenistan and Russia, thus very difficult of access and are laudably tri-lingual: Turkman, Russian and
English. All are splendidly illustrated with photos, plans, and drawings of the architecture and artifacts recovered. All are dominated by Sarianidi's expansive interpretations regarding the religious beliefs, ethnicity, and language of the residents of the BMAC (more on this below). A series of radiocarbon dates from a number of BMAC settlements place the civilization between 2200-1700 B.C. (but see H. Junger's article for radiocarbon dates of 2500-1700 B.C. in Kozhin et alii, 2010) (Fig. 2).

The quest for origins, though often said to be a secondary consideration, remains a primary focus of archaeological concern. The conceit of the archaeologist is to focus upon an ethnographic reconstruction of the past, a concern that transcends the ephemera of 'origins'. The question remains: When, Where and How did this archaeological entity originate? Within the con- 


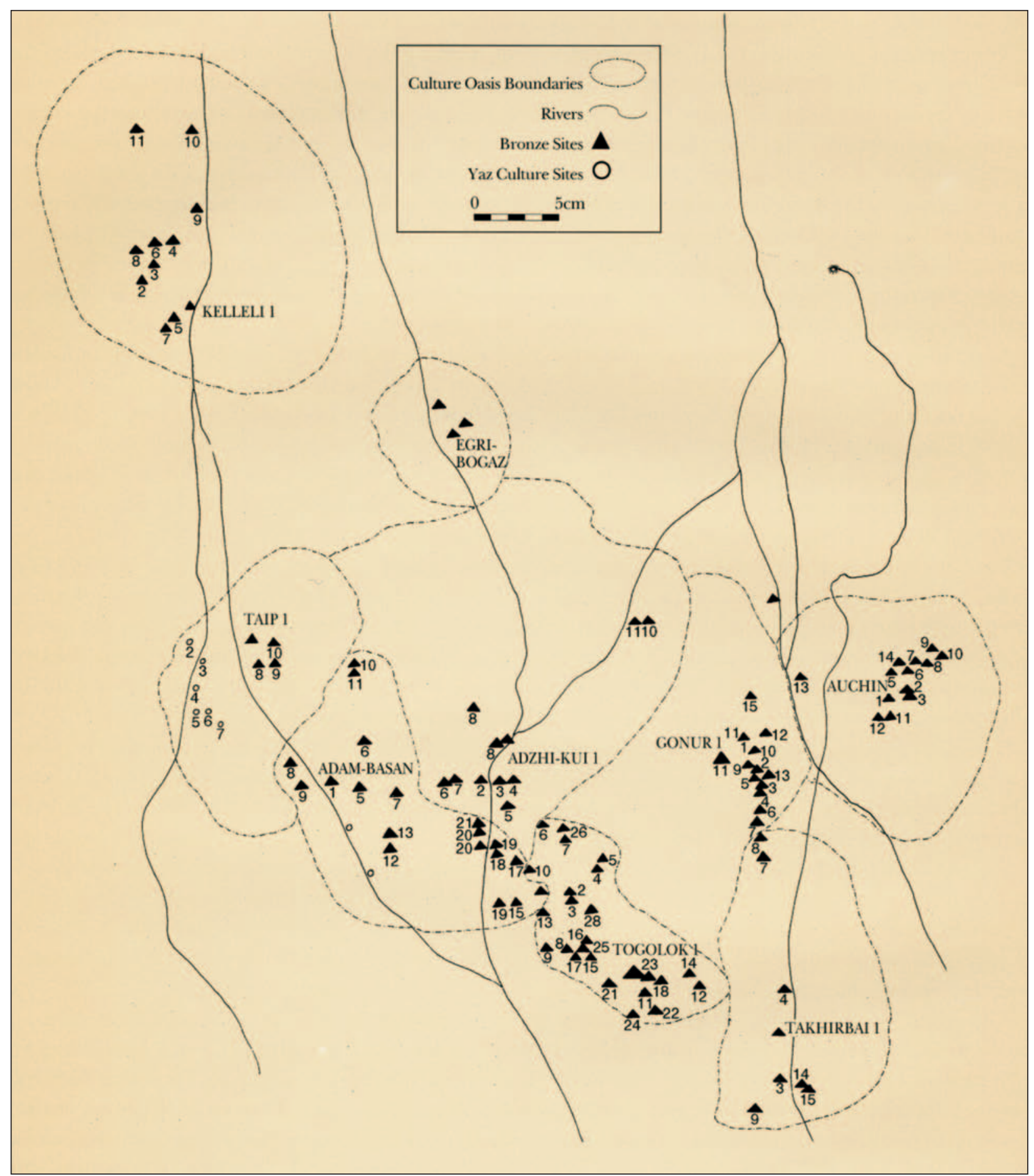

Figure 2. The riverine oases and major settlements of the Oxus Civilization (Sarianidi, 1998: 34 fig. 9).

text of the BMAC this is a vexing and much debated topic. Two hypotheses, their foreign vs. local origin, contend for attention - given present evidence neither can be conclusively affirmed or negated. Chronological distinctions, settlement size and pattern, relationship to irrigation, subsistence economy, and socio-political structure remain almost entirely unexamined. This is not due to the lack of excavation but to the research strategy pursued.

As to the origin of the Oxus Civilization the first hypothesis argues for a distant and foreign source. This view is championed by Sarianidi who believes their origin is to be sought in Anatolia. In his view a great migration of the future residents of the BMAC traversed 


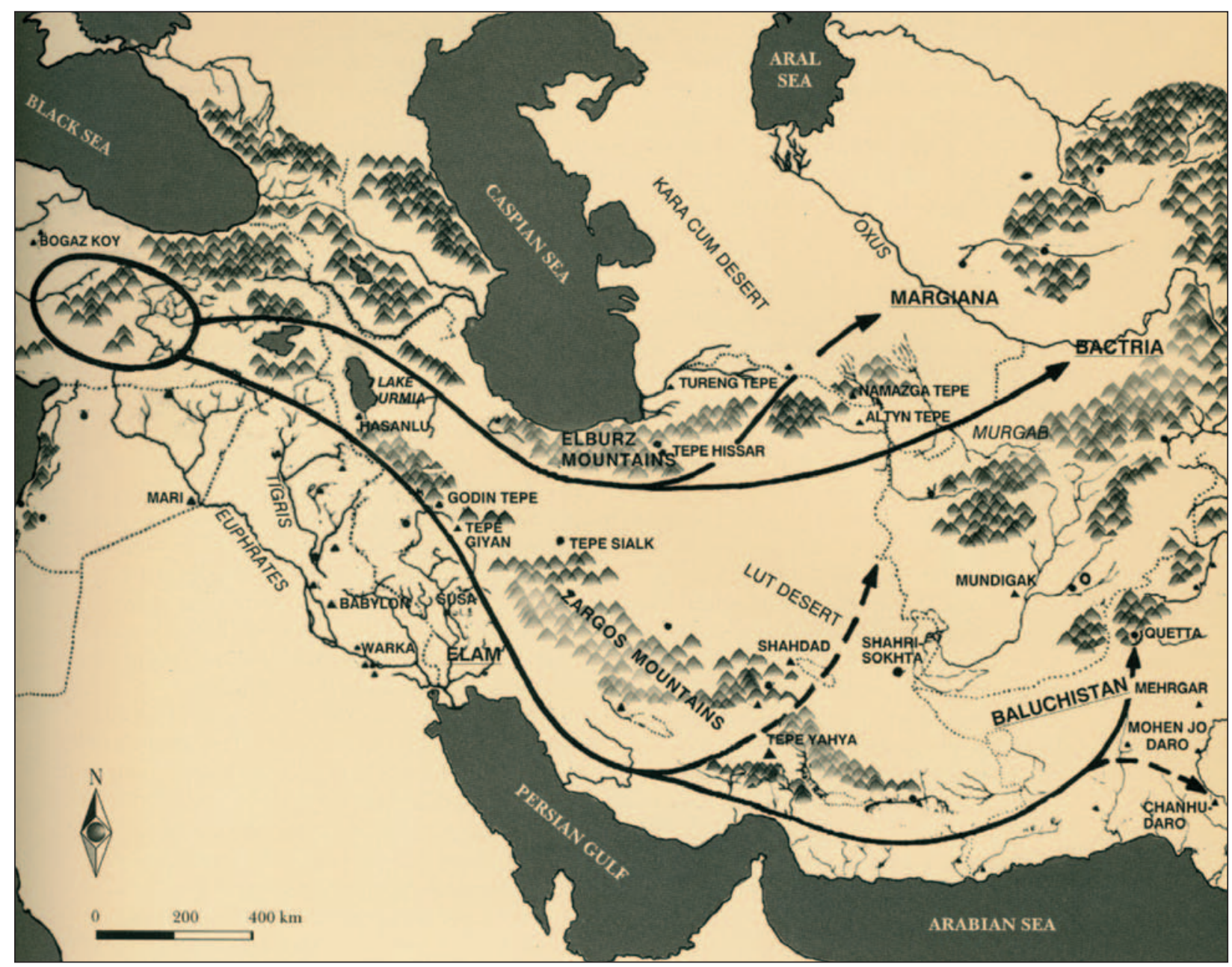

Figure 3. Sarianidi's hypothesis concerning the eastward migrations of the Oxus Civilization from Anatolia (Sarianidi, 1998: 163 fig. 75).

Mesopotamia where they "could not find free land", crossed the Iranian Plateau, and finally found their "free land" in the deltaic fan of the Murghab River (Fig. 3). Other tribes are alleged to have continued their migration to Northwestern China (Sarianidi, 2009: 42-43). Central to Sarianidi's imagination is his belief that the migrants were Aryans, specifically IndoIranians, who followed proto-Zoroastrian beliefs and rituals. Tentative support for the foreign emergence comes from Pierre Amiet (2004). Both entertain notions of BMAC affiliations (origins) with an Elamite world pointing to a number of archaeological sites on the Iranian Plateau that contain BMAC materials. Amiet identifies the BMAC as having a "TransElamite" identity, a culture of artisan nomads distributed across the Iranian Plateau to Central Asia. Steinkeller (see n.d. in bibliography) similarly entertains a diffuse origin from the Iranian Plateau.
In the last half of the third millennium, and for millennia before that, the Iranian Plateau was inhabited by a mosaic of distinctive cultures - all reasonably defined by the archaeological record (Petrie, 2013). Toward the last centuries of the third millennium a restricted inventory of BMAC artifacts appear on a number of sites on the Iranian Plateau and in the Indus Valley and the Persian Gulf: i.e.: Susa, Tepe Yahya, Shahdad, Khinaman, Hissar, Jiroft, Harappa, Mohenjodaro, and Tell Abraq. The archaeologist refers to the finds of BMAC materials on sites of an indigenous culture as "site intrusion", that is, artifacts restricted in number and type recovered from an indigenous culture. There can be little doubt that the BMAC influenced the indigenous cultures of the Iranian Plateau and the Indus Civilization, while in complimentary fashion numerous artifacts of the Indus and Iranian Plateau are known from Gonur depe (Sarianidi, 2009) (Fig. 4a, 4d, 4e). Note, however, that not 


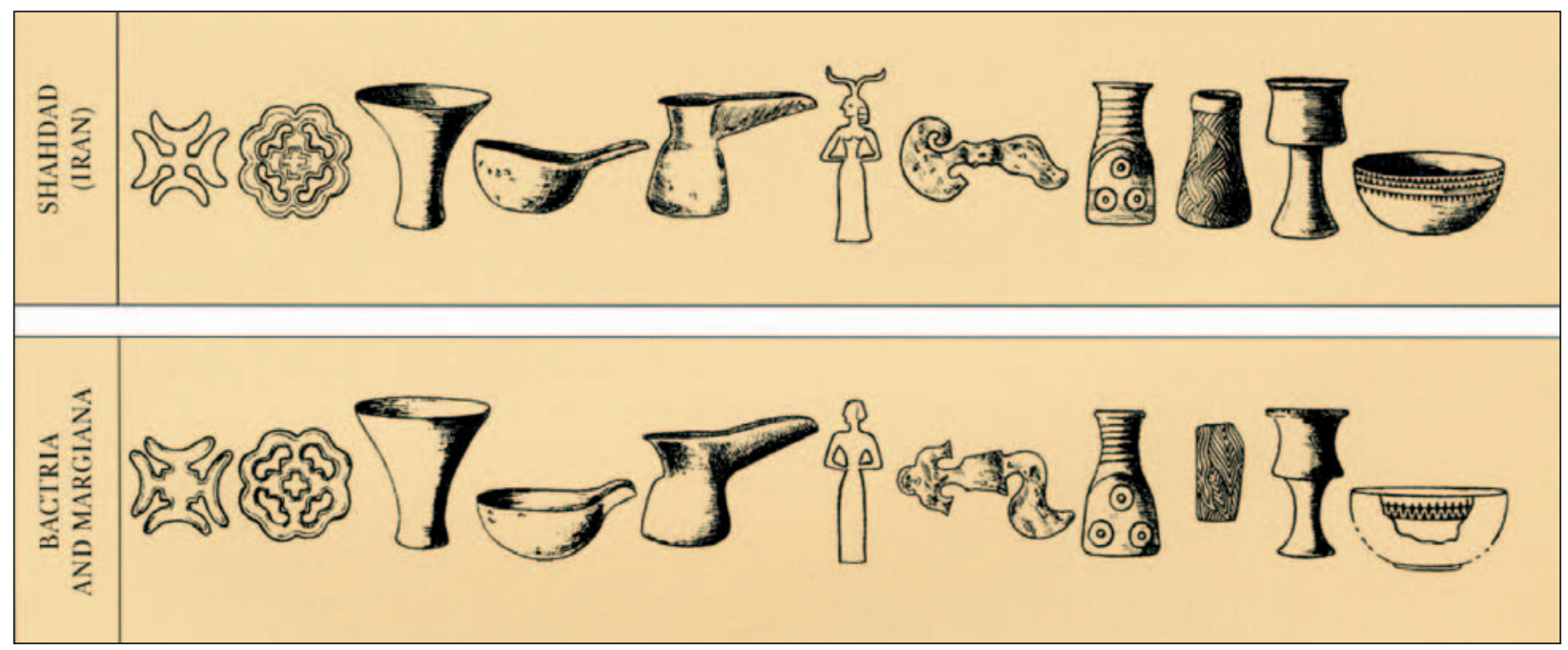

Figures 4a. Ceramic parallels between the Oxus and Shahdad, Iran (Sarianidi, 1998: 139 fig. 71).

a single BMAC artifact has been recovered from Mesopotamia while an inscribed Akkadian seal was recovered from Gonur depe (Sarianidi, 2002; 2005) (Fig. 4b). The view for a foreign, migratory origin of the BMAC simply lacks sufficient credible evidence. The distribution of a diffuse inventory of BMAC artifacts over a vast landscape offers little geographical focus for a point of origin. Amiet (1986) and to a certain extent Steinkeller's (n.d.) promotion of a trans-Elamite Culture (consisting according to Amiet of pastoral nomads) that identifies BMAC origins within the context of indigenous cultures of the Iranian Plateau simply does not stand up to the archaeological evidence. The BMAC is a wholly distinctive culture whose origins are to be sought in Central Asia not within the context of the cultures of the Iranian Plateau!

So we turn to hypothesis two; an indigenous origin. BMAC artifacts are, in fact wholly absent on important and contemporary sites of the
Iranian Plateau: Malyan (ancient Anshan), Godin Tepe and on all sites of NW Iran (on the Khorasan Road), while present at Susa they are absent on neighboring Choga Mish in Khorasan, and absent at Shahr-i Sokhta; while present at Shahdad they are absent at Yahya, Konar Sandal, and Bampur. On the Iranian Plateau where BMAC artifacts are recovered they are intrusive, a limited number of artifacts, found in the context of an indigenous local culture. One cannot demonstrate the existence of a shared trans-Elamite Culture on the Iranian Plateau only a limited inventory of intrusive BMAC artifacts recovered from distinctive cultures on the Iranian Plateau!

Hypothesis two argues for a local oases/piedmont origin. A rich post Paleolithic settlement of Central Asia begins with a mid-seventh millennium Neolithic (Dani and Masson, 1992). In the piedmont zone of the Kopet Dagh Mountains sites as Ilgynly tepe, dated to the fifth millennium, illustrate an elaborate metallurgy, an exceptional

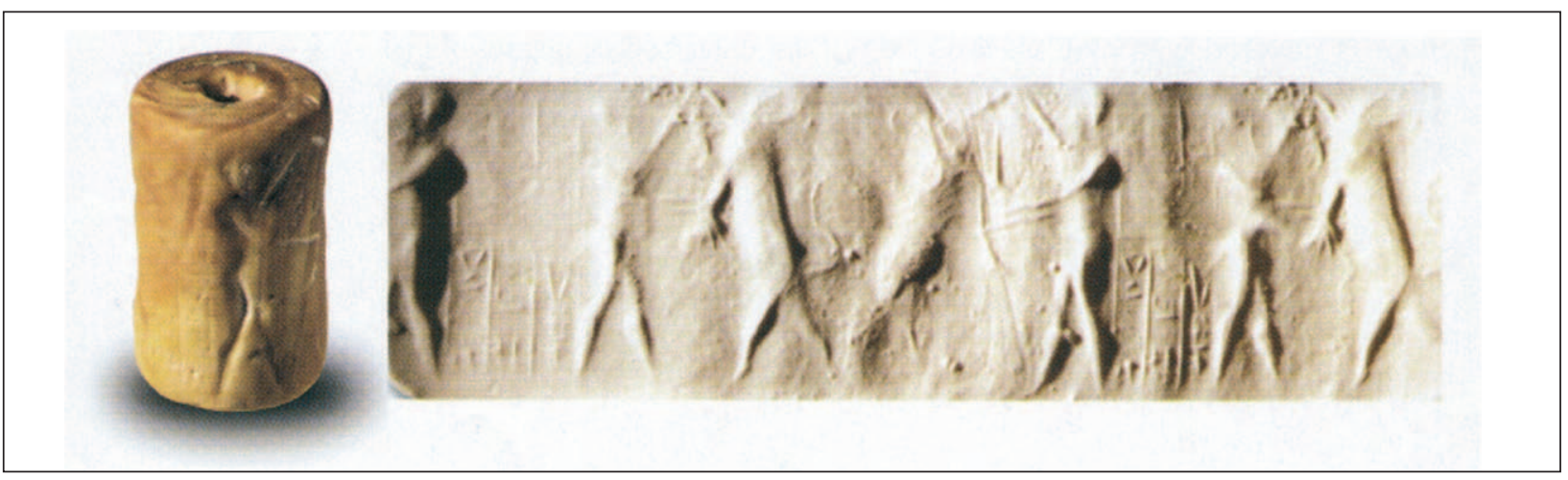

Figures 4b. Akkadian cylinder seal with inscription from Gonur (Sarianidi, 2005: 258, fig. 115). 


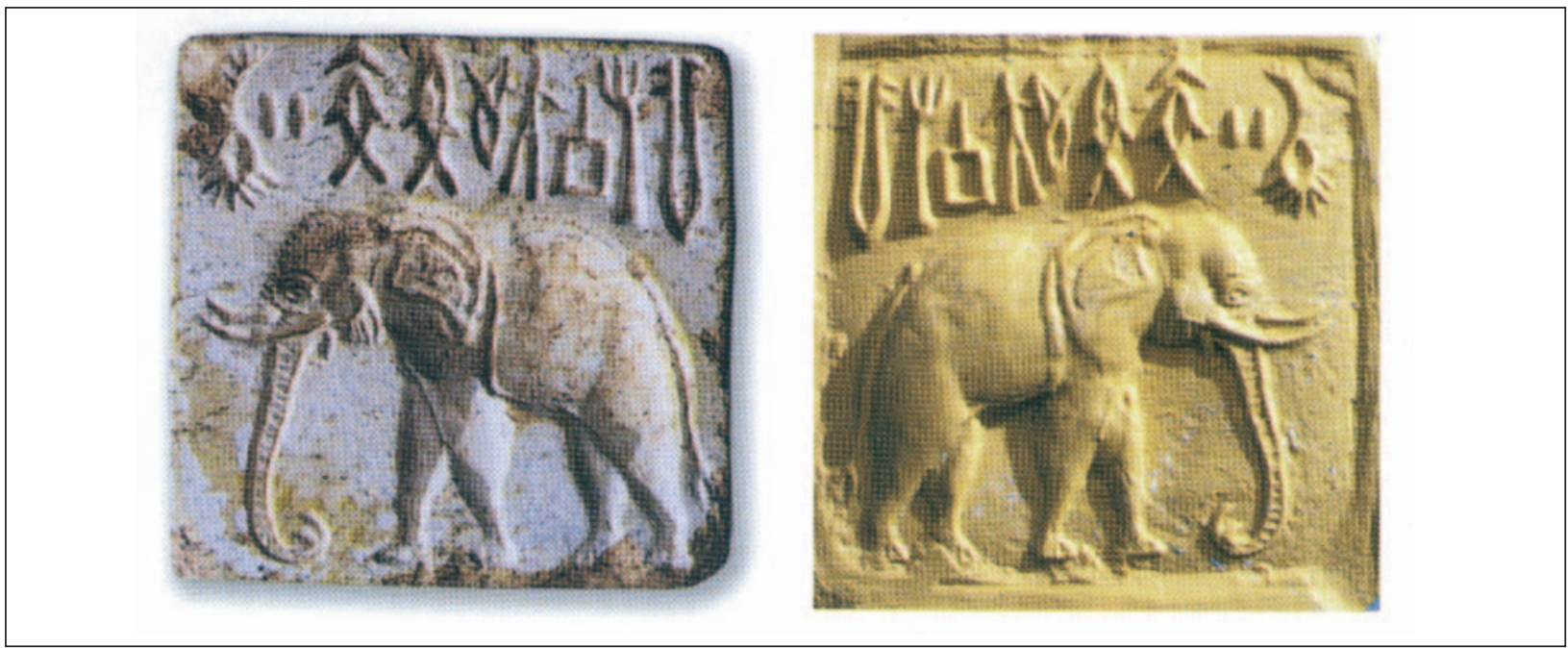

Figures 4c. Seal of the Indus Civilization from Gonur depe (Sarianidi, 2005: 258 fig. 114).

repertoire of figurines, complex mosaics within elaborate architectural features, all within a substantial settlement (Solovyova, 2005; Salvatori et alii, 2009) Impressive Chalcolithic and Bronze Age settlements, such as Namazga and Altyn depe, sustain urban populations throughout the $4^{\text {th }}$ and

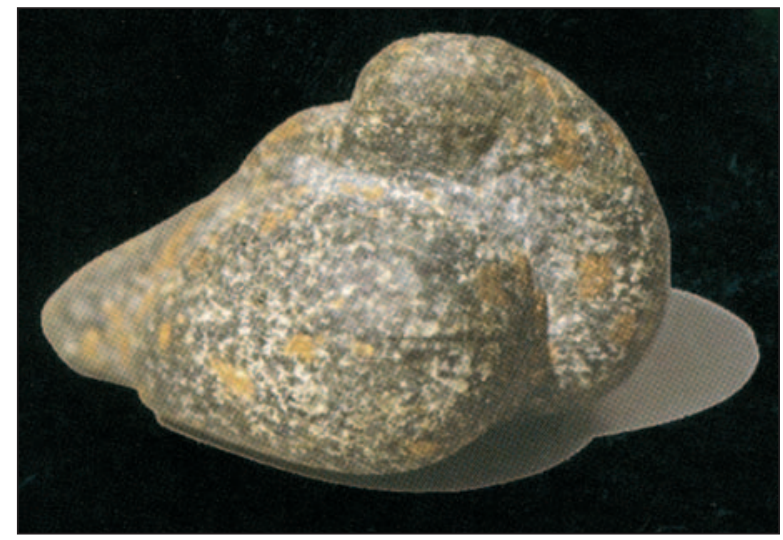

Figure 4d. Duck weight (?) from Gonur depe (Rossi Osmida, 2002: 100). $3^{\text {rd }}$ millennium. Excavations at Altyn depe, recently directed by Liubov Kircho (2008; Masson, 2001) suggest a local emergence for the BMAC. Furthermore, the BMAC was not the first to settle in the Murghab delta. Recent excavations at Adji Kui 1, directed by Gabriele Rossi Osmida (2008; 2011), indicate the presence of a distinctive earlier settlement, radiocarbon dated to ca. 2700 B.C. Stratified above that settlement are several fully fortified BMAC communities. The excavator argues for a local development of the BMAC. The indigenous nature of the Oxus Civilization is not, however, a new notion. Years ago Philip Kohl (1984) in an early and enduring review of the archaeology of Central Asia offered a compelling argument for a local origin.

The signature of the Oxus Civilization rests in its impressive architecture. More specifically, in the monumentality of the fortification systems that surround each settlement (Fig. 5). The sites

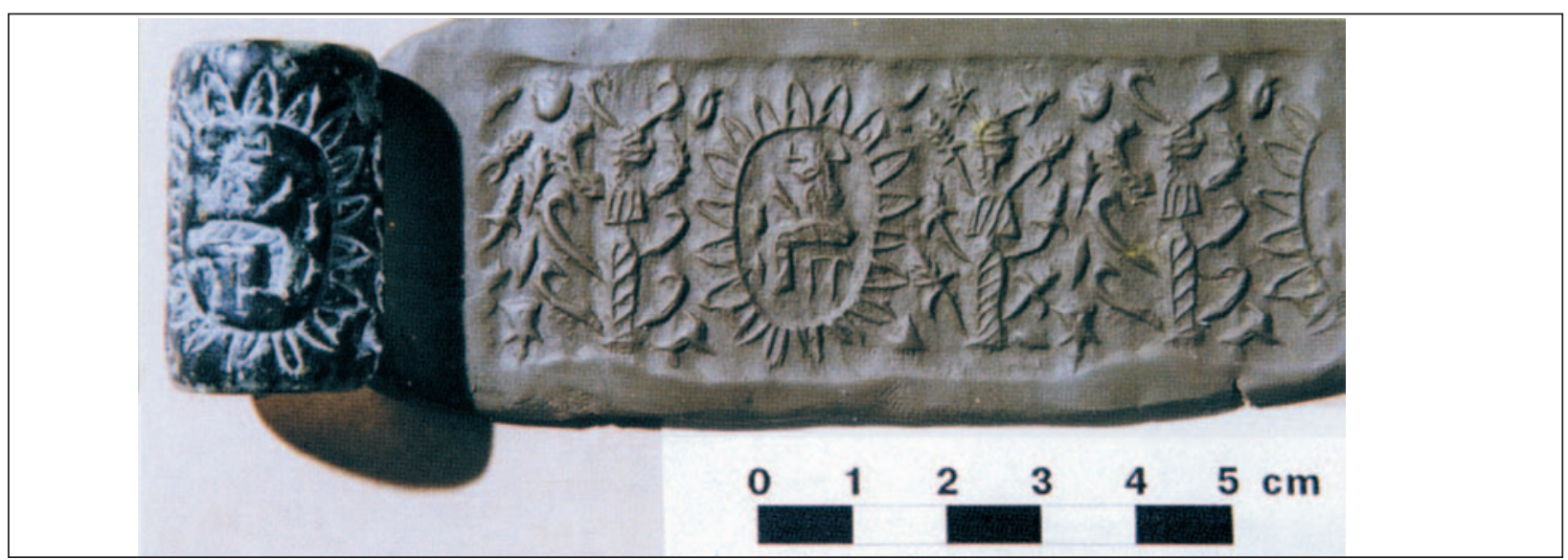

Figure 4e. Cylinder seal from the "Temple of Sacrifices", Gonur depe (Sarianidi, 2005: 283 fig. 137). 
of Gonur, Togolok, Adji Kui 1 and 9 serve as exemplary models of the extent to which the community was fortified. One, two, even three perimeter walls, most 2-4 meters in impressive width, enclose a community incorporating an area in excess of 20,000 square meters. Within this area at Gonur, Sarianidi identifies temples, palaces, areas of craft production, and ritual activities. Beyond this fortified area the community extended its walled settlement to $20+$ hectares. Gubaev et alii (1998) notes that numerous settlements surrounding Gonur were not fortified. Such an observation becomes dubious in light of the fact that fortification systems around Gonur could not be determined prior to excavation.
Contemporary communities, i.e. Adji Kui 1 and Adji Kui 9, are less than 3 kilometers distant from each other and are both well fortified, suggesting that even nearest neighbors, likely subject to a common authority, were fortified. Decades ago 12 sites were identified within a 20 x 20 kilometer region in the Adji Kui Oasis. This does not, however, accurately reflect the settlement regime of the oasis. Of the 12 sites initially surveyed only three survived the past 20 years of agricultural expansion, principally cotton production. Alluviation and an extensive agricultural development that began in the 1930s claimed the destruction of an unknown number of ancient settlements. Extensive alluviation,

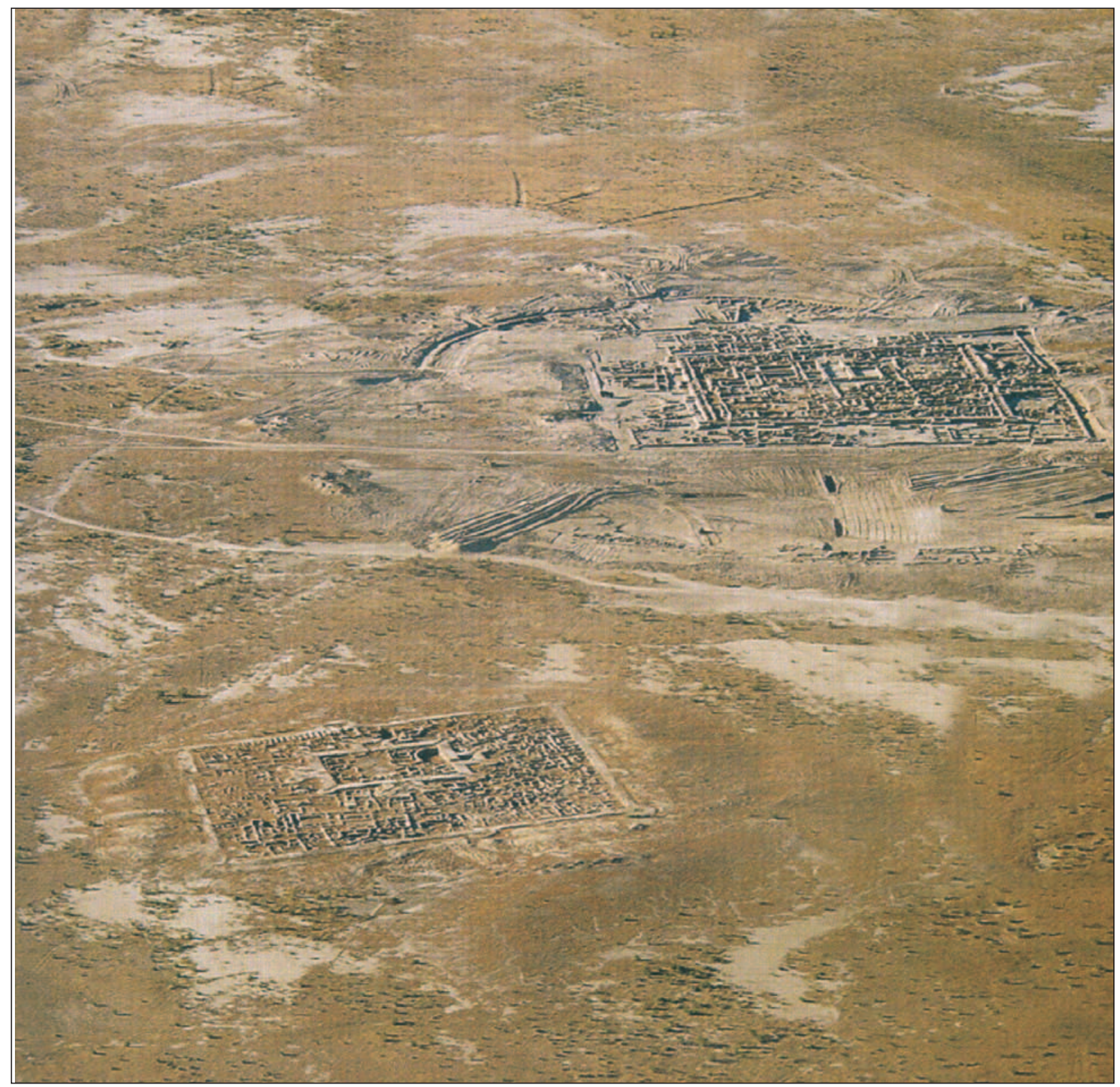

Figure 5. Aerial view of the excavation at Gonur depe (Sarianidi, 2007: 145). 
deflation, and the destruction of sites resulting from the reclamation of agricultural land prohibit the reconstruction of an accurate settlement regime. An approximation, however, of the dense settlement regimes within the Murghab delta during the Bronze and Iron Ages is hinted at in the archaeological surveys and maps produced over the past two decades by the joint Turkman and Italian missions (Salvatori and Tosi, 2008; Gubaev, Koshelenko and Tosi, 1998).

What do the elaborate and uniquely fortified communities of the BMAC signify and how do they address their social world? A cycle of violence must be entertained. Large urban centers such as Gonur and Togolok presided over satellite communities which were also fortified. Within the restrictive oases of the Murghab deltaic fan ecological constraints may have exacerbated needs for access to water, agricultural land and pasturage. Contests for the control of water and access to irrigation systems, amply documented at this time throughout Central Asia (Andrianov, 1969), fueled conflict for the control of limited land and water resources. Ethnographic and historical sources offer instruction and ample analogies. In the later Iron Age and medieval period a characteristic feature of the landscape was the Qala - a large fortified community serving as the residence of the local Khan and a defensive retreat for the community in times of attack (Lamberg-Karlovsky, 1994; Szabo and Barfied, 1991: 162-163) in their comprehensive study of architecture offer the following definition for the qala: "The dwelling type known as the qala originated as a fortified farm compound with thick, massive outer walls in square or oblong plan averaging $40-80 \mathrm{~m}$ per side of $6-8 \mathrm{~m}$ in height. At each corner is a defense tower rising approximately $1 \frac{1}{3}$ times the height of the walls (...) multistoried dwelling and storage spaces are constructed against the outer walls with the doors and windows facing a central compound (...) [with] single entry gate (...) Each qala is a selfcontained unit providing shelter and protection for an extended family, their farm animals, and the provisions necessary for survival".

Such is a fulsome description of the BMAC architectural template. For centuries the largest of qala's was the center of political authority, a focus of craft production, a facility for the storage of surplus products, and the residence of the tribal leader, family and retainers (Tolstov, 1948). The remarkable persistence, and last remnants, of the Central Asian Qala and its associated social structure, is readily documented in $19^{\text {th }}$ and $20^{\text {th }}$ century Afghanistan (Barfield, 2010). In his study of the BMAC the architectural historian Mohammed Mamedov (2003: 41, 139) observes that the monumental architecture was built on a "definite modular plan", oriented to the cardinal points, while the size of bricks is the same as that found on earlier sites ("Aeneolithic Age") in the Kopet Dagh, suggesting a local Central Asian continuity of architectural construction. He further observes that the architectural features of BMAC fortifications, both monumental and domestic architecture, involved "the same planning principles that formed the basis of many monumental constructions of Central Asia from the antique and medieval periods that subsequently survived in folk architecture until the middle of the $20^{\text {th }}$ century"

A $19^{\text {th }}$ century description of these qala's and the central role they played in opposing the Russian annexation of Central Asia is vividly described in the books of Mac Gahan (1874; Schuyler, 1876; O'Donovan, 1882). Schuyler (1876, II: 381) writes: "These forts were in all probability intended to protect the aqueducts [irrigation systems] and the tilled land from incursions of nomads". In 1881, between January 12$24^{\text {th }}$ a tsarist army under the command of General Mikhail Skobelev laid siege to the large rectangular fortress of Geok Tepe. It was the last Central Asian territory, defended by the Tekke Turkman, to fall to tsarist Russia. The population of the surrounding countryside gathered in a fortress with an uncanny resemblance to those of the BMAC. The Turkman are said to have suffered losses of 14,500 before surrendering to General Skobelev. O'Donovan (1882) was an eyewitness to the Geok Tepe battle and offers a vivid description of that confrontation. His observations on the fortifications are of interest (O'Donovan, 1882, II: 143) "The fortifications were of the kind which the populations of these Central Asia plains seem to have constructed from time immemorial and the remnants of which one still sees scattered far and near" and "it was the intention...to concentrate themselves and their families within the fortress in case of invasion" (O'Donovan, 1882, II: 146) and, finally, "each man having his musket slung on is back as he follows the plough or harrow" and "on the first alarm of an inroad, the oxen are hurriedly driven under the walls of one of the for- 
tified towers which dot the country" and "place themselves within the fort to protect their property by the fire of their muskets (O'Donovan, 1882, II: 62-63). Of equal interest is his observation on the association of forts and irrigation. In discussing the great Dam of Banfi and its nearby fort, the Baba Kabasi, he states 'without this dam the present cultivated area would be reduced to a condition as bleak and arid as that of the plains that surround it (...) the old Sarouk fortress (...) constituted the central stronghold of Merv [the principal city along the Murghab], and protected the water-works" (O’Donovan, 1882, II: 175).

The Merv Oasis which constitutes the apex of the Murghab deltaic fan is about 40 miles in width and length and constitutes approximately 1, 600 square miles, being the largest of the Oases within the BMAC horizon. In the $19^{\text {th }}$ century Henry Lansdell (1885: 476-477) gave the width of Murghab around Merv as "80 to 100 paces" and up to "23 feet" in depth. The presence of a large dam "diverts the water among the two sections of the oasis by means of two main canals, the Otamish and the Tokhtamish (...) each of the two canals distributes water through about 50 leading arteries, and these in turn feed hundreds of smaller leats".

Each of the two canals was occupied by different clans of the Tekke tribe, themselves divided into 17 distinct branches. Additionally, the Merv Oasis was inhabited by clans of the Akhal, Saryks, Salors, Ersaris "and others" totaling " 230,000 souls" in a state of continuous tribal conflict. Nineteenth century travel literature describes a settlement regime, a pastoral nomadic context, an omnipresent irrigation network, and the presence of fortifications protecting settlement and waterworks that appear to mirror their Bronze Age counterparts (Fig. 6).

Today the stratified BMAC site of Adji Kui (Rossi Osmida, 2002; 2008) offers the best evidence for the chronology of the Oxus Civilization while Gonur, also a stratified site, offers the most extensive horizontal exposure and material inventory. At Gonur the numerous publications of Sarianidi (see bibliography) present the site as consisting of a single period, without stratigraphic or chronological distinctions (Salvatori, 2010; Lamberg-Karlovsky, 2003). Although Sarianidi (2003: 206-208) writes of different building levels, i.e. as many as four temples built on top of each other (Sarianidi, 2009: 99, fig. 17-18) no effort is made to publish materials from distinctive strata. Regrettably, even after more than thirty years of research and excavation, the chronology and stratigraphy of the BMAC remains deeply problematic. The principle sites excavated Gonur, Togolok and Sapeli, to mention but three, did not attend to stratigraphic distinctions nor are the limited number of radiocarbon dates associated with specific stratigraphic levels or material inventory. Gonur depe, subjected to over 30 years of excavation and with 1000s of square meters of architecture exposed to various depths is published as a single period site. Its material inventory, different building levels, and cemetery with over 2500 burials exposed, is published as a contemporaneous inventory. The $\mathrm{C}-14$ dates, often derived from unspecified contexts, bracket a range of 2100-1700 B.C. In his $85^{\text {th }}$ year, Victor Sarianidi, with relentless energy, enthusiasm, and a vivid imagination, continues to excavate at Gonur. To date he has published more than a half dozen books on Gonur. His imagination populates Gonur with kings, priests, temples and palaces. The inhabitants of Gonur are identified as Aryans, specifically undifferentiated Indo-Iranians. Parallels to architecture and materials remains are drawn with Syria, Anatolia, and Greece. The inhabitants of Gonur are identified as adhering to "proto-Zoroastrian" beliefs, while architectural features, ceramics and small finds are taken to be evidence for Zoroastrian ritual behavior. Temples abound: 'the Northern and Southern Water Temples', 'Fire Temples' the 'Solar Temple of Mithra', the 'Temple of Sacrifices', the 'Temple of Communal Eating' and the 'Temple for Soma/Haoma'. The 'Temple of Mithra' is said to contain a 'solar altar' (a not unusual hearth with ample ashes) and a composite figurine "found nearby' identified as Arshtat, Goddess of Justice. Such conjecture is sufficient to reach the conclusion that "the origin of Mithraism should be looked for in Bactia and Margiana' (Sarainidi, 2008: 121) (Fig. 7).

Sarainidi's evidence for the presence of SomaHaoma in each of these 'temples' is loosely conceived. Soma-hoama is the hallucinogenic (?) drink favored by Indra, the God of Battle, mentioned in the RgVeda as a "god of Gods" (RV 9.42). The most comprehensive and influential study involving the much contested identity of Soma-Haoma, including a review of the related linguistic, Vedic, historical, and ethnographic material, is that of Harry Falk (2003). He con- 


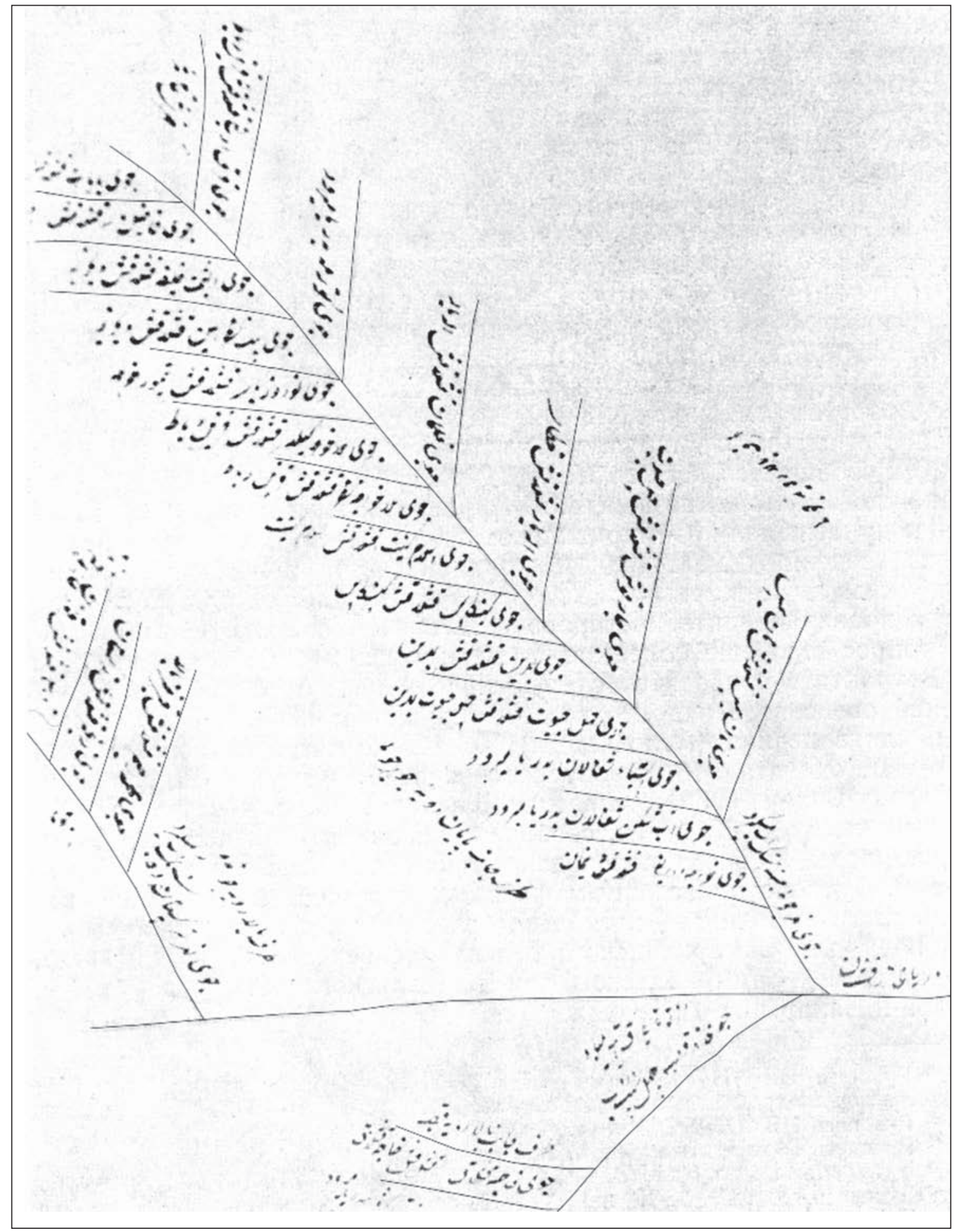

Figure 6. Medieval irrigation system of canals controlled by specific tribal lineage

(Muhammedjanov, 1978: 130 fig. 19).

cludes that for Soma-Haoma "there is no need to look for a plant other than ephedra, the one plant used to this day by the Parsis", the present day Zoroastrians of Iran and India. In 1995, Sarianidi claimed to have found ephedra twigs in a vessel uncovered at Gonur. In 1998 a second discovery of ephedra was reported as accompanied by poppy seeds and cannabis. Analysis of both finds of ephedra could not confirm its identification (see Houben, 2003 for the 1995 analysis and Bakels, 2003 for the second identification). As with the 'Temple of Soma-Haoma' the identification of numerous other "temples" rest more on allegation than on demonstration. In each and 


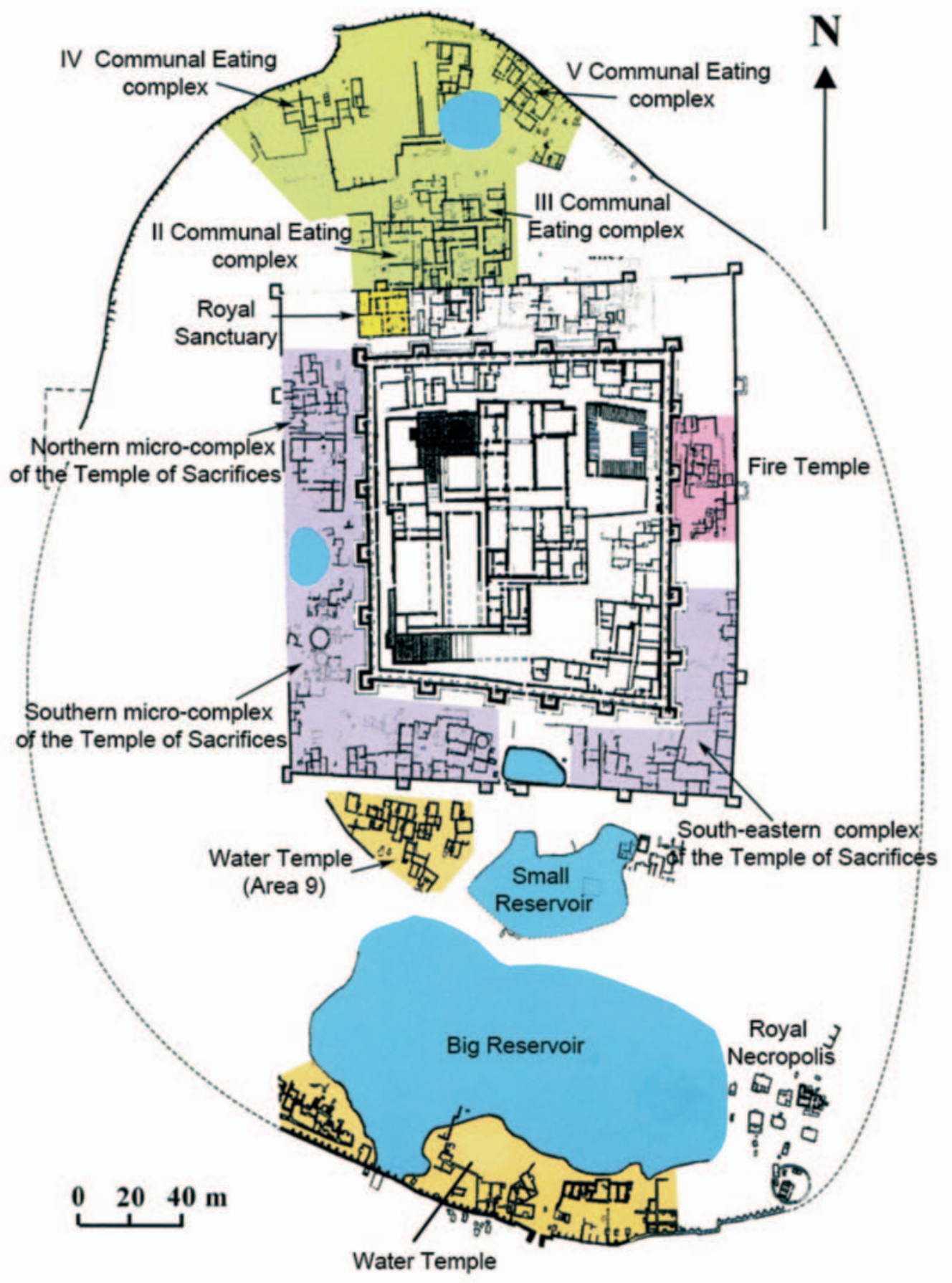

Figure 7. The "palace" of Gonur depe and associated "temples" (Sarianidi, 2005: 31).

every case the identification of a "temple", or specialized activity areas, i.e. the area for "communal eating", numerous and distinctive "ritual hearths", a "dakhme-mausoleum" (an area for the exposure of the dead), and different types of "ritual vessels" are all identified as conforming to the functions of Zoroastrian ritual. Of special interest are two designated "Water Temples". These are in fact sizable reservoirs, the 'Northern Water Temple' being $180 \times 80 \mathrm{~m}$, in which water was directed to the center of the fortified community. The unique discovery of a man-made reservoir within a heavily fortified community would advantage its survival when under siege and serves further notice on the need for strategies of survival. 
The so-called 'Palace of North Gonur' contains rooms 91-94 and in the "backyard of the kings residence a dakhma-mausoleum with royal burials" (Fig. 8). The ten "royal burials" exposed in these rooms are of outstanding interest. Many individual burials appear to be accompanied by a sacrifice of the "communally dead". Human sacrifice of "slaves" is paralleled to the Royal Tombs at Ur (Sarianidi, 2008; 2009).

Tomb 3220 may be singled out for its exceptional wealth as well as for problems concerning context and association. A "royal residence and

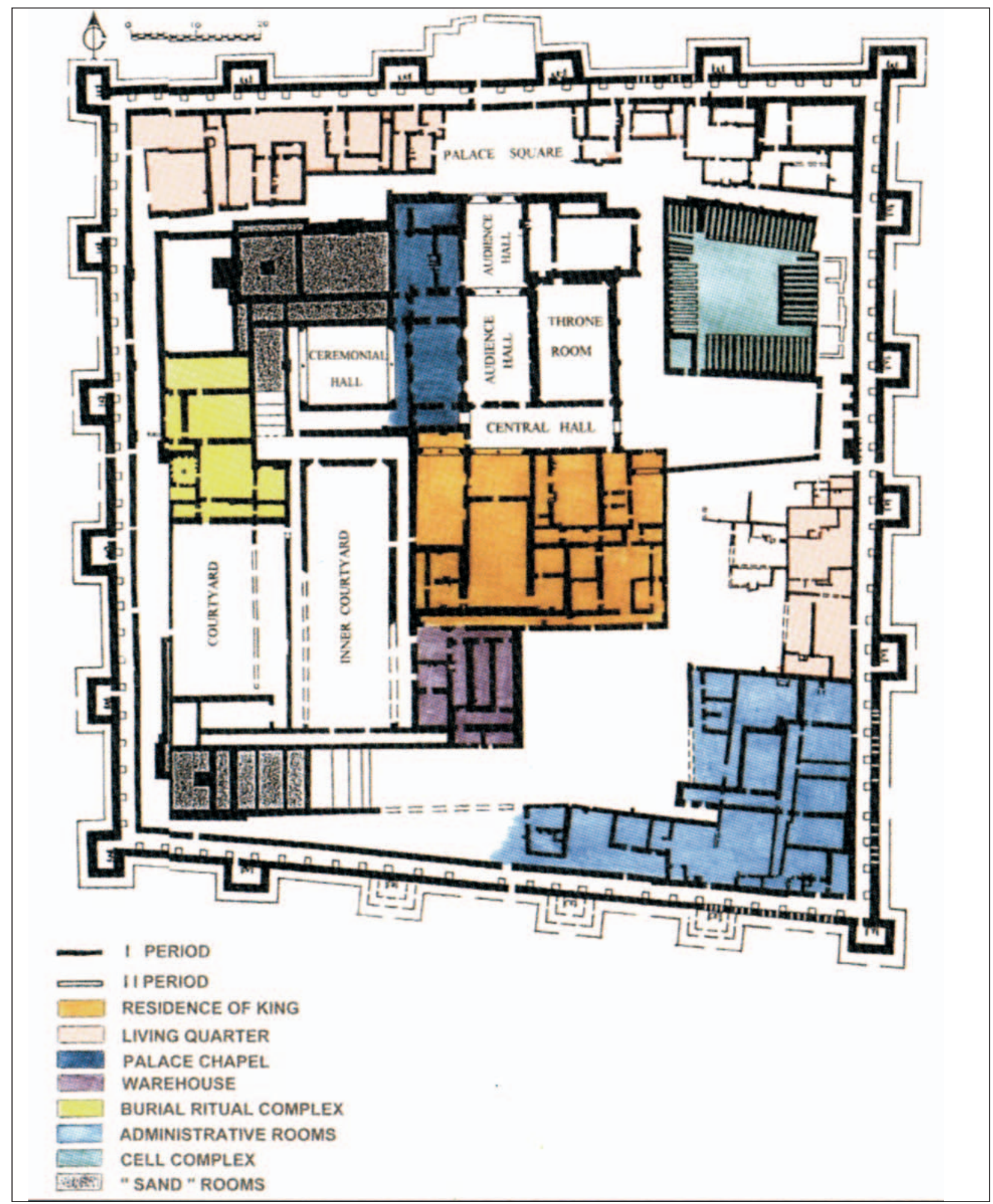

Figure 8. The "palace" of Gonur depe (Rossi Osmida, 2002: 19). 
royal necropolis" are said to be dated to the last centuries of the $3^{\text {rd }}$ millennium. The tombs are described as "underground miniature houses" and believed to attest to the fact that "only Indo-Aryan tribes make burials in the shape of underground houses" (Sarianidi, 2009: 192-194). But are they really burials in "underground houses" or are they houses with burials beneath the floor? The houses have all the features of living houses, hearths, cooking areas, sherds on the floor, etc. and the burials are recorded as beneath the floor of the houses. In the rich burial of 3220 the actual burial was found "half a meter beneath the floor of the house" together with 24 vessels: 2 gold, 17 silver and 5 bronze (Fig. 9a-d). One of the large silver vessels had a procession of two Bactrian camels

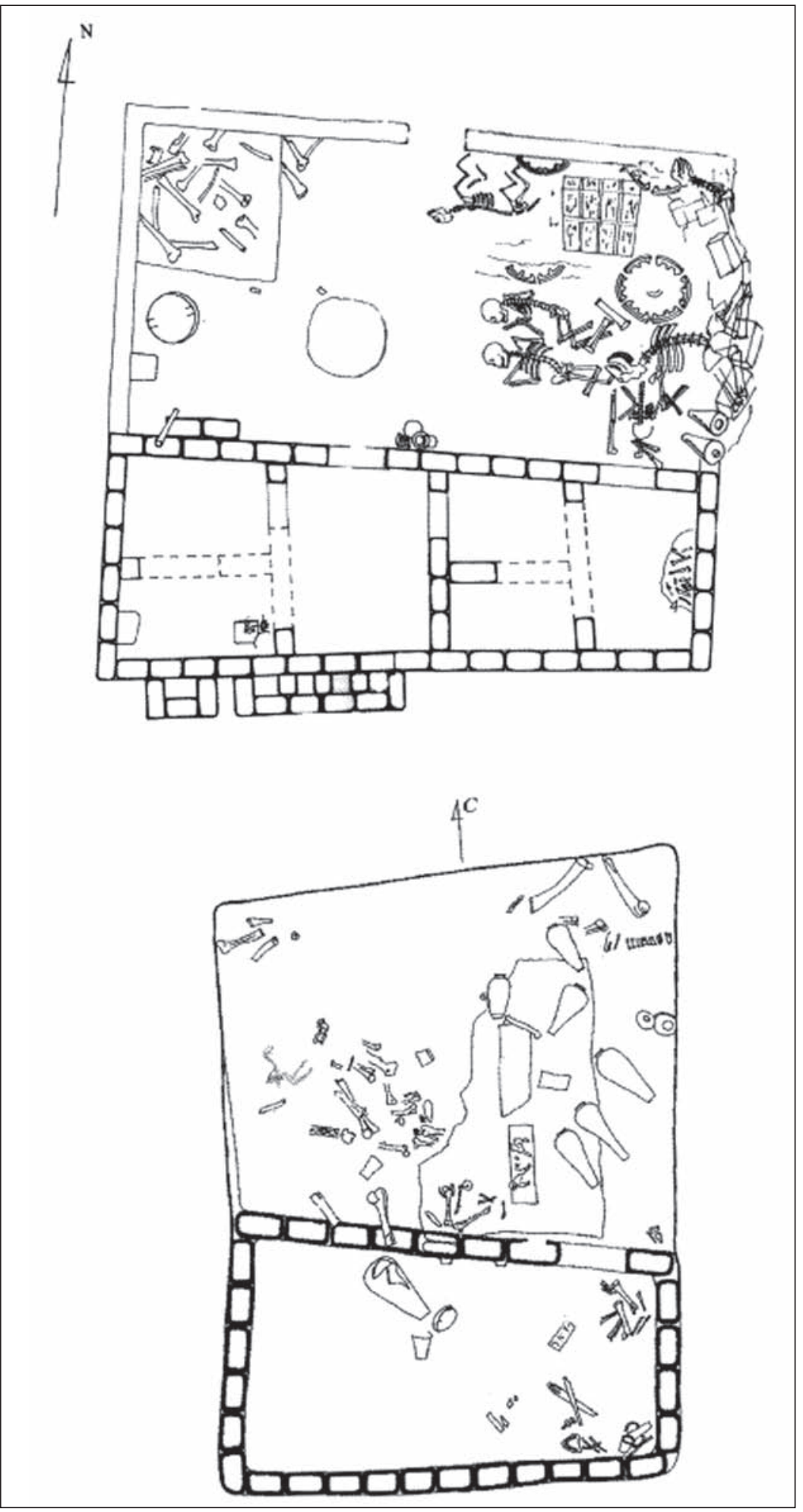

Figures 9a. The "Royal Cementery" at Gonur, Tombs 3200 and 3210 (Sarianidi, 2009: 151 fig. 63-64). 


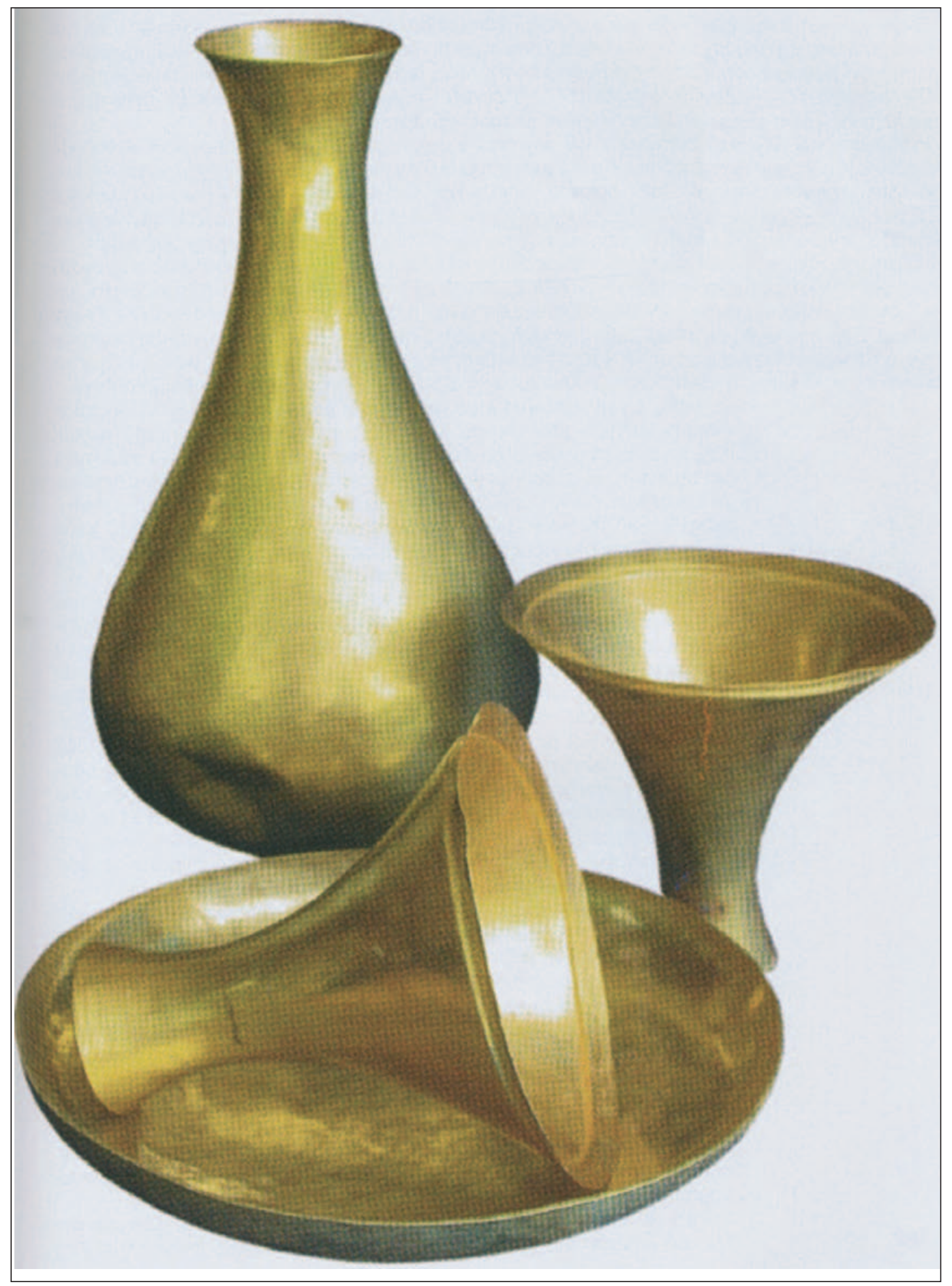

Figure 9b. Gold vessels from Gonur, Tomb 3220 (Sarianidi, 2009: 161 fig. 73).

in relief and an incised Bactrian camel at its base. The author's dubious contention that this is the earliest illustration of the Bactrian camel permits him to suggest that "we have the grounds to give them another name -camel's margiana". Burial beneath the houses, as well as outside the house within "yards" are commonly reported. Thus, in burial 3235 the burial is over a meter beneath the floor and contained 7 vessels: 2 gold, 3 silver and 2 bronze. Many additional fine artifacts were discovered in the "yards" that were outside these subterranean "burial houses". In "royal grave" 3200 "gifts were found in the yard and to the East from the central gates of the tomb a four wheel 


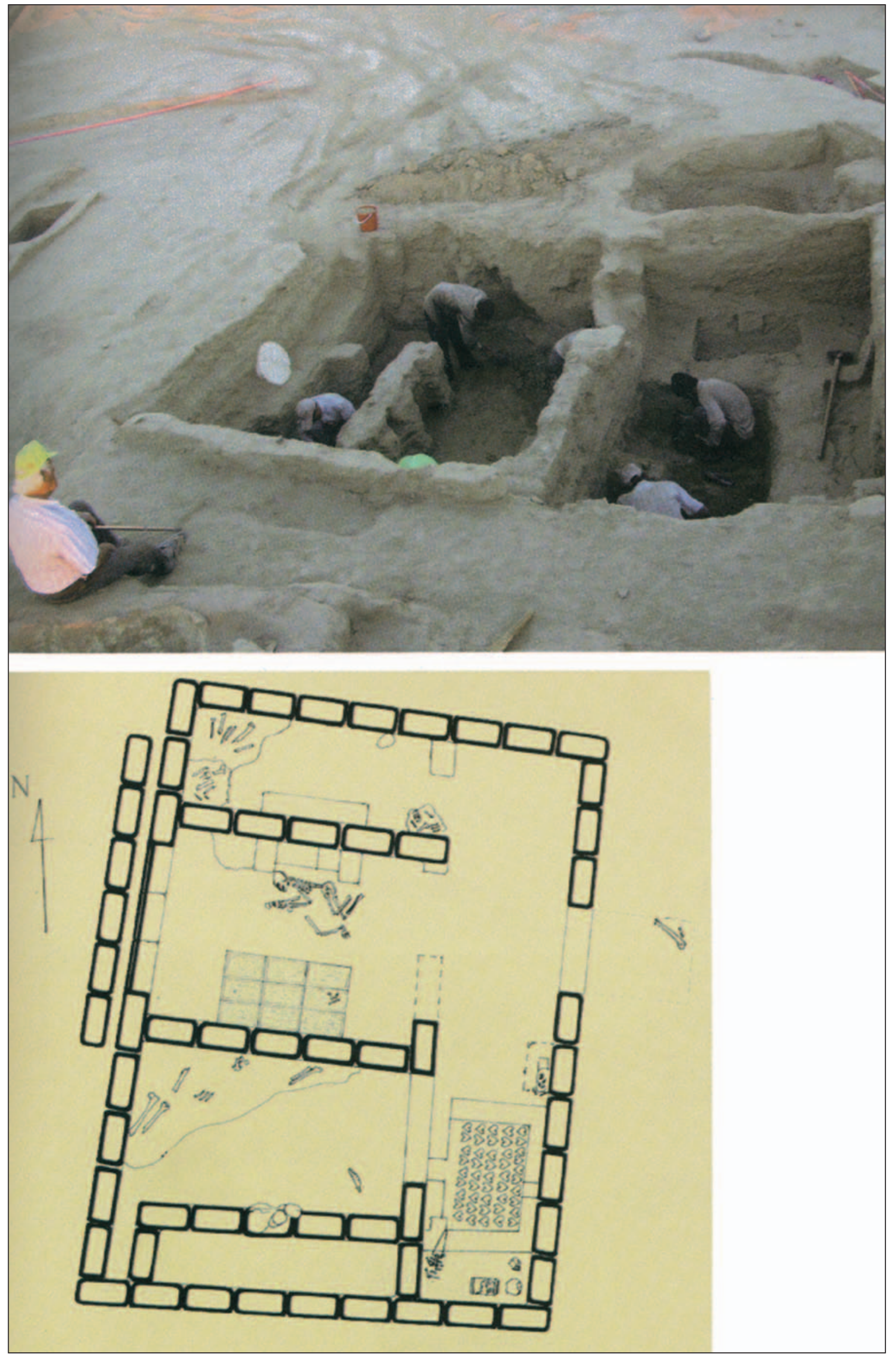

Figures 9c. The "Royal Cementery" at Gonur, Tomb 3220 (Sarianidi, 2009: 153 fig. 66-67). 


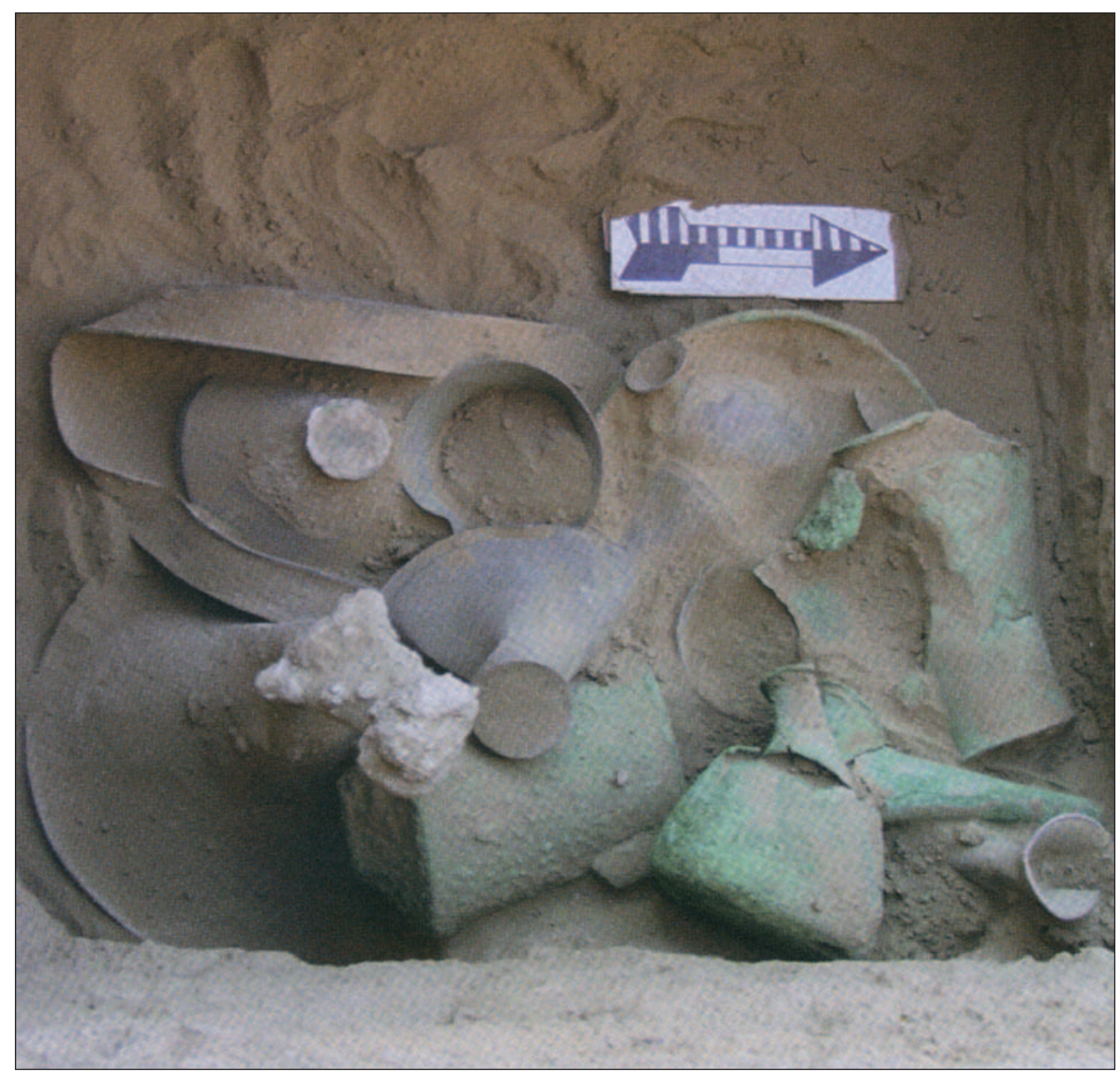

Figures 9d. Silver, gold and bronze vessels from Gonur, Tomb 3220

(Sarianidi, 2009: 160 fig. 72).

cart was found". The cart, unillustrated, is claimed to be the earliest cart recovered in the Near East (Sarianidi, 2009: 197). Royal tomb 3225 also contained a cart with "human sacrifices" of "slaves and servants" (Sarianidi, 2009: 198-200) (Fig. 10a). In burials classified as "pitgraves", burial 3240 contained 15 skeletons while 3235 had eight skeletons all said to be sacrificial victims. The sacrifice of camels, dogs, sheep and horse (tomb 3200) is also reported. Tomb 3210 contained a splendid $86 \mathrm{~cm}$ mosaic frieze of opposed lions (Fig. 10b). It was discovered in the "yard" of the tomb floating 1.5 meters above the floor level. Tomb 3210 contained a silver "signal trumpet (...) for training of domestic horses"; one of five trumpets recovered (Sarianidi, 2009: 324, fig. 184) (Fig. 10c).

Sarianidi does not offer zooarchaeological evidence for the presence of the domesticated horse at Gonur. Equids are certainly present but are they equus caballus? To date, only the onager and the domestic donkey (equus asinus) are known to be present at Gonur (Moore, 1993; Meadow, 1993). The presence of Andronovo pottery at Gonur, the characteristic ceramics of the Eurasian steppes where the modern horse was domesticated, certainly implies that the horse was known to the BMAC. Sarianidi, however, tends to disregard the influence of the steppes and holds that the "horse appeared not from the local steppes but rather 

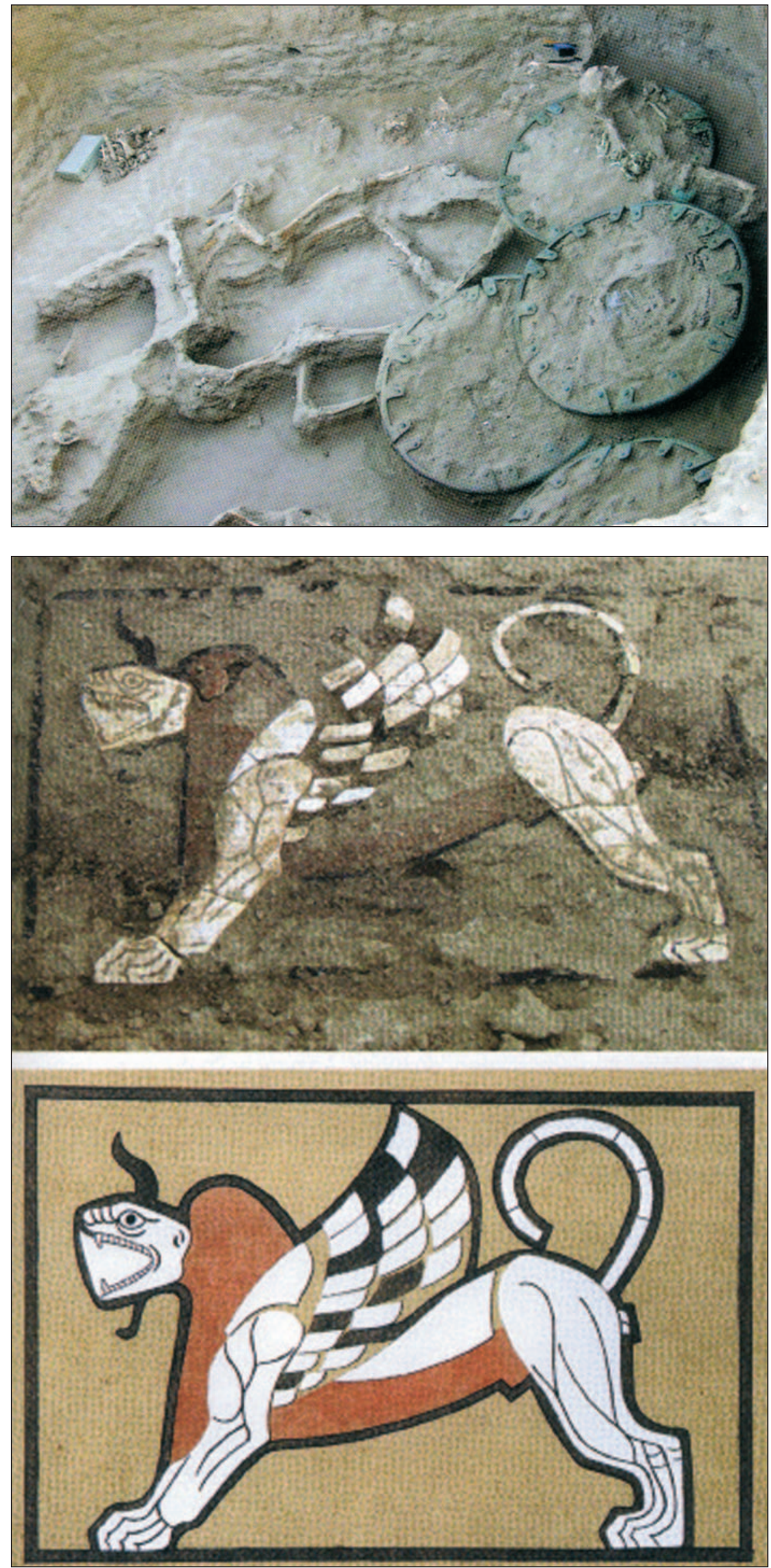

Figure 10a. Wagon burial from Gonur, Tomb 3225 (Sarianidi, 2005: 240 fig. 99).
Figures 10b. "Winged lion" mosaic from Gonur, Tomb 3210

(Sarianidi 2009: 211 fig. 122-123). 


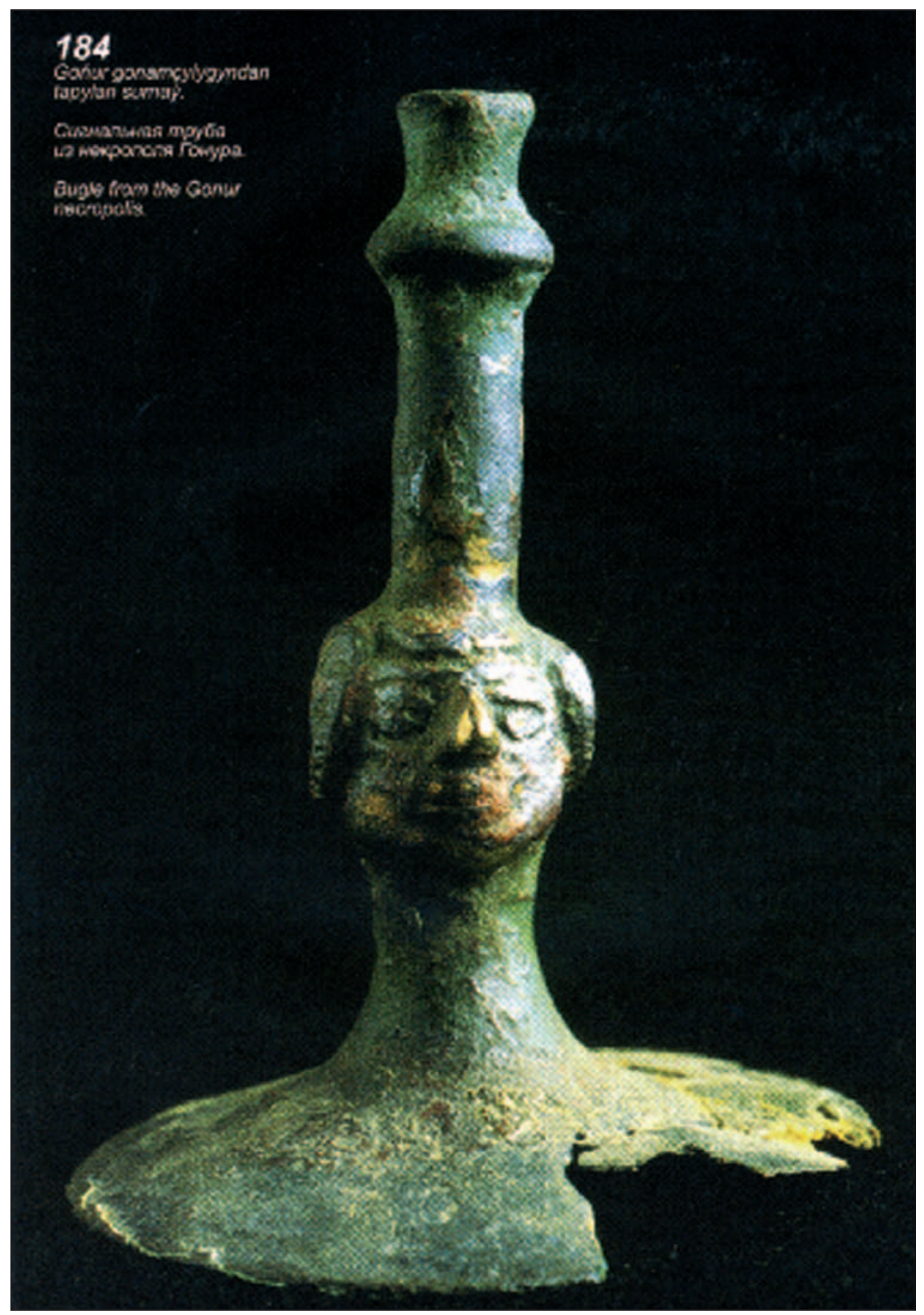

Figure 10c. A bronze trumpet from Gonur depe (Sarianidi, 2009: 324 fig. 184).

from the advanced center of the world and first of all from Asia Minor and presumably from the modern area of Syria" (Fig. 11a-b). Why?

Problems of context and association arise from the author's description of the finds within the tombs. Thus, grave goods from the "Royal Tombs" are reported as coming from the "very upper layer', "upper layers", "lower layer", "floor", "yard" and "under the floor" of the "burial houses". Royal tombs were ten in number while the cemetery, extending over 10 hectares, and containing 2853 excavated tombs, had $2.1 \%$ "cist graves", 11\% "pit graves", and $85.1 \%$ shaft graves (Fig. 12). Secondary burials are also reported and said to "resemble closely the funeral rites described in the Avesta" [the sacred book of the Zoroastrians] (Sarianidi, 2010: 236). Irrespective of date, context, and association, the 

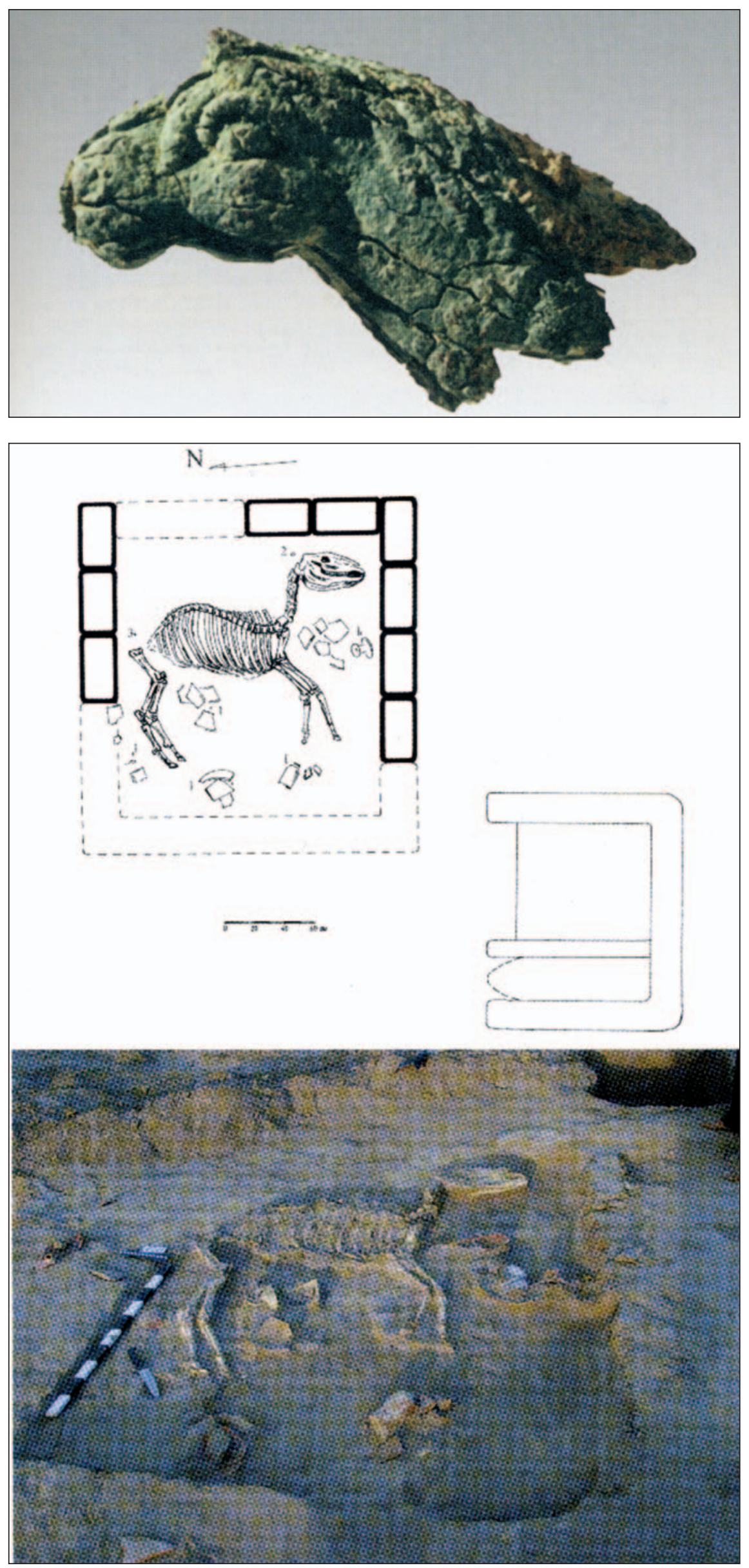

Figure 11a. Horse's (?) head of bronze from Gonur depe (Sarianidi, 2002: 237).
Figures 11b. Burial of a horse (?), Tomb 3340 in "Royal Necropolis" at Gonur depe (Sarianidi, 2008: 411 fig. 223). 


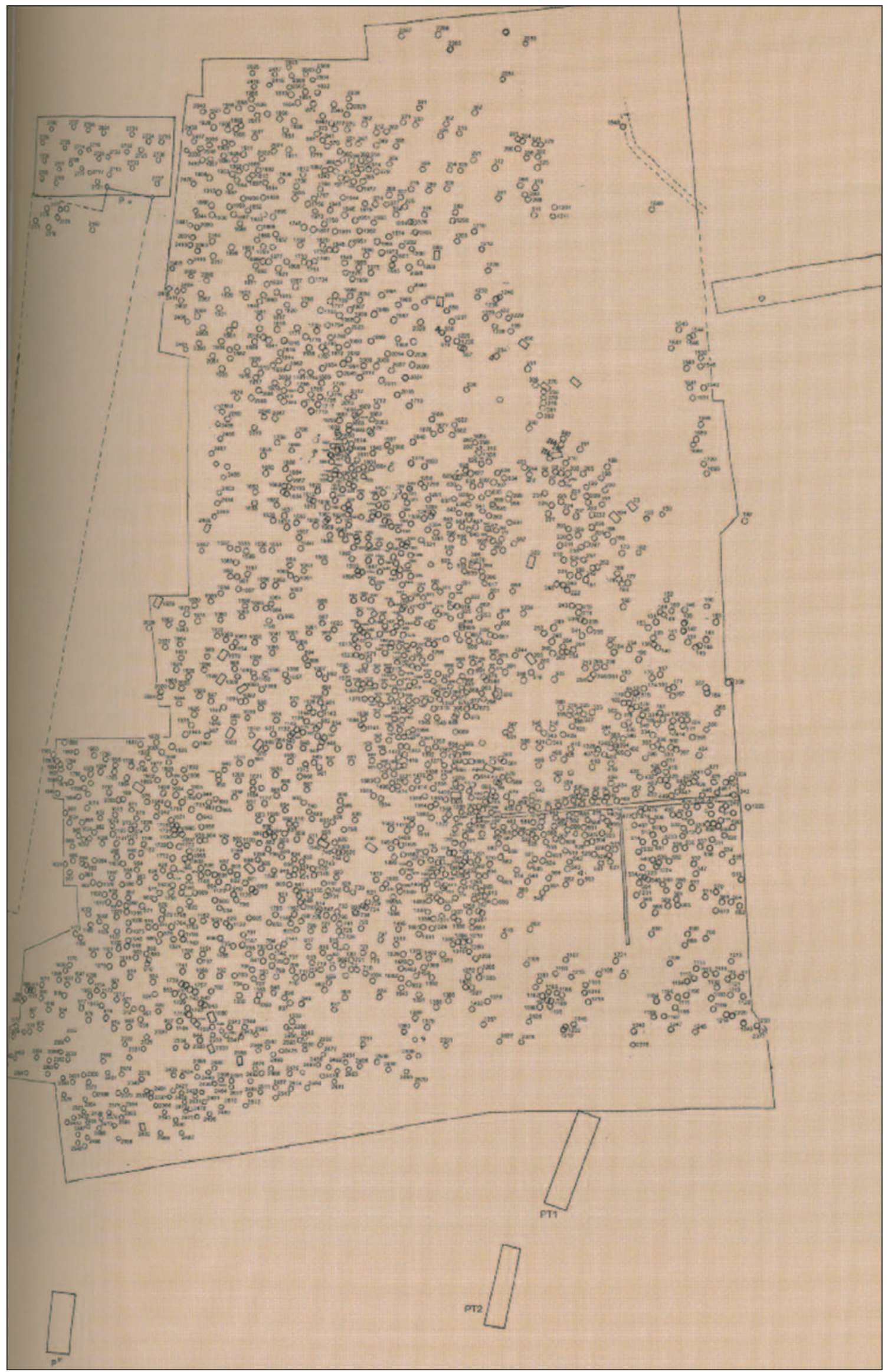

Figure 12. Excavation of the Gonur cemetery (partial view) (Sarianidi, 2007: 22-23). 
materials recovered from the tombs are of exceptional interest, representative of the highest achievement in craft manufacture, and equal in aesthetic production, to anything produced in the Bronze Age Near East. The richness, both with regard to technological achievement and aesthetic quality is abundantly demonstrated in the ten "Royal burials".

Virtually all the materials recovered within the BMAC, whether of gold, silver, bronze, lapis lazuli or carnelian had to be imported from considerable distance. Some objects consisted of multiple materials as a "hairpin" consisting of a flower with golden petals, ivory, lapis and an iron (meteoric) stem (Sarianidi, 2009: 185, fig 94) (Fig. 13). Foreign contacts, whether they be gift exchange or attesting to commercial relations are evident in the recovery of an Indus seal (Sarianidi, 2005: 258, fig. 114), depicting an elephant and inscription, and an Akkadian seal also with inscription (Sarianidi, 2005: 258, fig. 115). The inscription, as read by T. Sharlach, states "Lucaks a holder of the cup and servant" (Sarianidi, 2002: 334). Foreign objects recovered from the Indus Civilization are relatively rare, however, BMAC statuary and seals are attested at Mohenjodaro and Harappa while numerous sites on the Iranian Plateau contain ubiquitous BMAC artifacts: Shahdad, Hissar, Khinaman, Yahya and Susa (Amiet, 1986, 2004; Potts, 2008; Hiebert and Lamberg-Karlovsky, 1992). The absence of a single BMAC artifact in Mesopotamia is surely trying to tell us something. But what?

In Sarianidi's (2009) recent book the author acts as a tour guide and offers a description and interpretation for what the viewer would observe in visiting Gonur depe. Each of the objects observed and the architectural complexes 'visited' is given what Searle (2010) calls a "status function" resulting from the fact that "humans have the capacity to impose functions on objects". At Gonur our tour guide imposes an a priori "status function" to specific artifacts, ceramic vessels, and architectural complexes all functioning within specific Zoroastrian rituals. The validity of these "status functions" are surrounded by the concepts that Sarianidi imbues them with, namely, a Zoroastrian world of Aryan mythology. Concepts embed artifacts and buildings with meaning, and, just as there is no money without the concept of money, there is no status function to any artifact or building at Gonur without the concept of
Zoroastrian religion and Aryan ethnicity. For Sarianidi it is these latter concepts that give 'meaning' to the material world of Gonur.

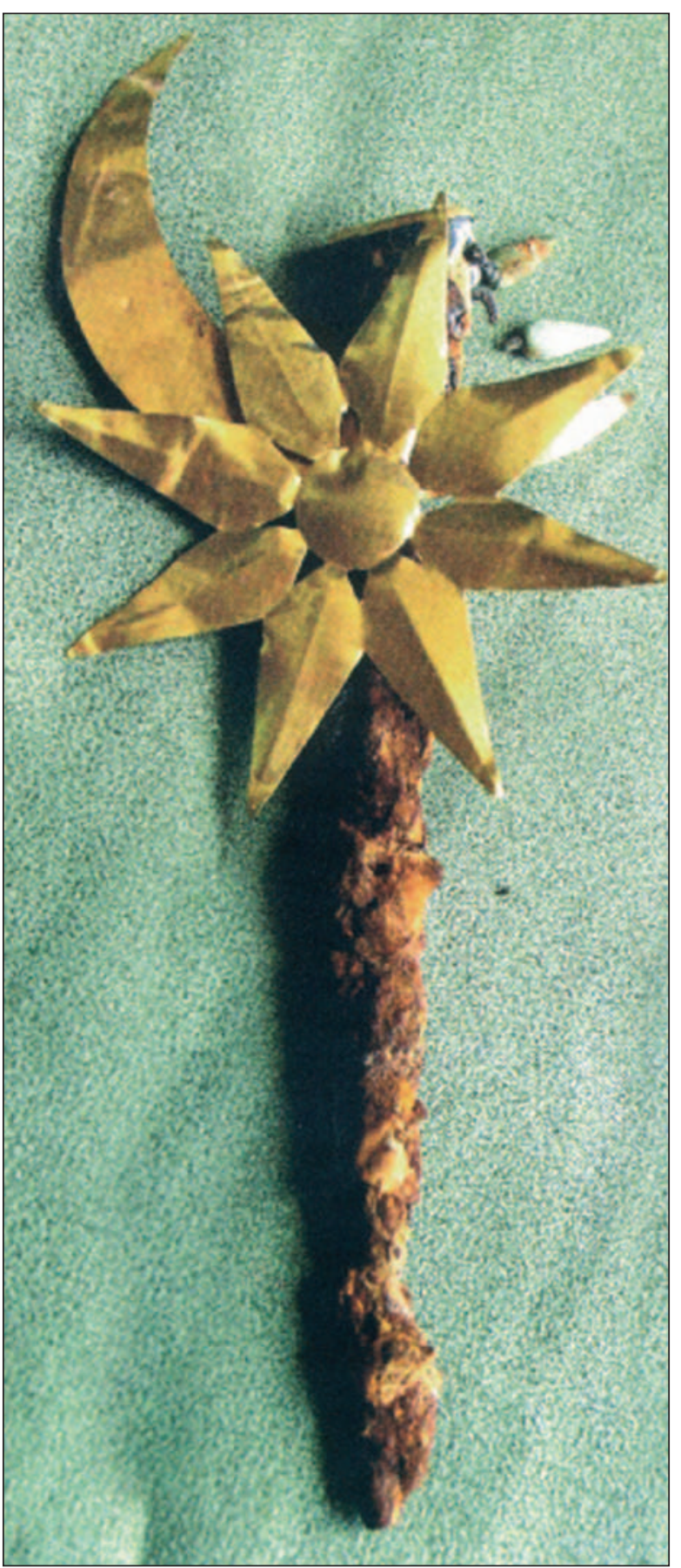

Figure 13. Iron shalt and golden pommel from Gonur depe (Sarianidi, 2009: 185 fig. 94).

Doubtless concepts do imbue 'facts' with meaning. In this regard Sarianidi's 'facts' follow from the application of the concepts he adopts. Gonur's very materiality, its pottery, hearths, burial patterns, metallurgy, kilns, architectural features, even reservoirs are given 'meaning' within a world of 
Zoroastrian and Aryan concepts of ritual and belief. Our Gonur guide offers a rich narrative of interpretation but his narrative is virtually void of demonstration beyond personal authority. Allegations regarding the "status function" of Gonur's material inventory rest entirely on the concepts he imposes upon this imagined Aryan and Zoroastrian community.

In adopting concepts to explain an archaeological complexity does Sarianidi differ from an epistemology of archaeological practice? The answer would be 'No'. For example: the concept of the 'State' is believed to be given an archaeological presence by the identification of a 3-4 tiered hierarchy (village, town, city) of settlement. The nature of that state, however, remains entirely unexplained. Thus, a specific settlement hierarchy equals a 'State' but the socio-political structure of that state remains wholly unexplained. An archaeological identification of an emperor with no clothes! As Ian Morris (2011: 135ff) observes for the past, as well as for the present, size alone does not indicate complexity, let alone organization. Today Lagos is the size of New York City yet is lacking in organizational complexity, bureaucratic systems and institutional structures. A settlement hierarchy tells one absolutely nothing as to the structure of that state: kingship?, dictatorship?, theocratic?, democratic?, etc. In each of the above 'states' one imagines their definition by modern examples. The BMAC cannot be aligned with any of the above 'states' and must give way to its own definition. We may surmise that it was, like all Bronze Age states of the ancient Near East, without defined boundaries, subject to the absolute and arbitrary rule of the leader, embedded in the importance of kinship, legitimized by divine sanctions, and finally, as David Hume observed royal power maintained its right as the sole institution of "force and usurpation". Like the $19^{\text {th }}$ century khanates of Samarkand and Bukhara, and some states today, we may fairly call it a coercive 'mafia state'. The state is being viewed as the property of the ruling elite. Settlement regime, pattern, or hierarchy, had nothing to do in the past or in the present with a privileged identity or definition of the state!

Concepts of fertility, ancestor worship, female figurines, plastered skulls, irrigation systems, and monumental architecture, conjure-up certain $a$ priori interpretations. Within the PPNB plastered skulls are taken, on ethnographic analogy, to be evidence for ancestor worship. Alternatively, appealing to another line of ethnographic evidence and one that casts a darker shadow on our appreciation of the PPNB, is their interpretation as war trophies. How to choose between material evidence that address different 'concepts'? Processual archaeology in its emphasis upon the ecological and material largely avoided addressing social concepts while the post-processual approach allows for any narrative, any 'trope', to offer 'meaning' which, of course, differs from explanation. Just think of how the archaeological record has been changed, confirmed, and contested by the introduction of the concept of 'feminism' or 'Orientalism'. Sarianidi consistently inhabits the 'hermeneutic circle' wherein interpretation, meaning and ideology are the very substance of his narrative. The materiality of his BMAC world is interpreted as embedded in Zoroastrian beliefs and rituals. Ceramics, architectural features and entire complexes, as well as individual artifacts, are given a meaning by alleging them to have Zoroastrian functions. Beyond allegation and personal authority there is little evidence to support his interpretations. Unwittingly, Sarianidi is the most post of post-processual archaeologists. His is an imaginative narrative in which allegation trumps demonstration.

While Sarainidi inhabits the Aryan world of proto-Zoroastrian Gonur with a rich interpretive context he all but ignores the economic subsistence patterns, environment, settlement pattern, landscape, and the socio-political world of ancient Gonur. Again, an important case in point: is the horse, equus caballus, present at Gonur? Sarianidi would have us believe that it is, for its presence in an Aryan world is a sine qua non. Though the presence of the modern horse is alleged we have little evidence that the zooarchareological remains from Gonur were systematically recovered or studied by specialists. A brief summary of faunal remains is published by Sataev (2008).The same pertains to the paleoethnobotanical remains (for the best early review see Moore, 1993; Meadow, 1993 and Moore, Miller, Hiebert and Meadow, 1994; For more recent analysis of wood, botanical remains, C-14, metal and ceramic analyses see Sarianidi, 2008b) and for metals (Kanuith, 2006).

There can be little doubt that irrigation played a significant role in the agricultural production of the Oxus Civilization. Today the entirety of the 
Murghab deltaic fan is interlaced by irrigation canals dedicated to the production of cotton. The linear pattern of settlements within the BMAC suggests their placement along major canals of the deltaic fan and along extended irrigation canals within the oases. For an early comprehensive study of ancient irrigation systems within the Chalcolithic and Bronze Age of Central Asia see Litsitsina (1965) and Andrianov (1960).

The cultural geography of the Iranian Plateau, as seen from the Mesopotamian texts, is a richly contested landscape. Is the BMAC mentioned in the third millennium texts? Recently, Daniel Potts (2009) has answered the question in the affirmative. He suggests that the Oxus Civilization is not only known but frequently mentioned as 'Shimashki'. On the other hand, Steinkeller (2007), reading the same texts, and Henrickson's (1984) study of archaeological settlement patterns, place Shimashki on the eastern slopes of the Zagros Mountains in western Iran. To further complicate the issue Henri-Paul Francfort and Xavier Tremblay (2009) identify the Oxus Civilization as Marhasi, mentioned along with Shimashki in late third millennium texts as important kingdoms. Marhasi, in turn, has been identified by Steinkeller (1982) as located in southeastern Iran, in the region of the Jiroft, i.e., incorporating the sites of Konar Sandal, Shahdad, and Tepe Yahya (Madjidzadeh and Pittman, 2009). The location of Shimashki may be contested but its importance leaves no doubt. In alliance with the Elamites the Shimashkians brought to an end, by military conquest, one of the most powerful dynasties of the third millennium: the Ur III Empire (Potts, 2009).

While the Oxus Civilization may have played a role in the demise of the Ur III Empire it did not sustain its own continuity long after that event. By 1700 B.C. virtually all of the fortified settlements of the BMAC are abandoned. Pottery of the so-called Takhirbay Culture, mid-second millennium, does bear some similarity to the BMAC while its settlement regime and material culture are essentially different (Piankova, 1993 for bibliography), suggesting that 'collapse' is more of a 'process' than an 'event' (Mcanany and Yoffee, 2010). The collapse of the BMAC is not a much considered topic. Two hypotheses have been advanced, neither with strong supporting evidence. The first argues for a progressive deterioration of the environment resulting from a reduction of water flowing from the Pamir Mountains. This factor is believed to be coincident with an advance of sand brought into settlements and irrigation canals by the prevailing northern winds (Salvatori, 2008). The second 'causal' factor is seen in an increasing pastoral nomadic presence and concomitant hostile relations. Settlement surveys record an increasing incursion of nomadic encampments, the so-called "Andronovo Question" in proximity to BMAC settlements (1800-1500 B.C.) (Cattani, 2008). There is, however, little, if any, evidence for conflict between the BMAC and the ephemeral pastoral nomadic presence. The final Bronze Age, the Takhirbay 3 phase of the second half of the second millennium, is said to document a dramatic reduction of sites in Margiana/Bactria and an integration of the sedentary communities (descendents of the BMAC?) and pastoralist populations (Kuzmina, 2007: 211-291，2008; Piankova, 1993).

Over the past decade Gabiele Rossi Osmida has been excavating BMAC sites in the Adji Kui Oasis: the fortified settlements of Adji Kui 1 and 9. He makes an important distinction as to the nature of the two settlements. Adji Kui 1 is referred to as a "farm" (Fig. 14a-b). Impressive fortification walls surround the settlement. The central core of the fortified settlement is occupied by individual houses, large two-storey circular kilns for firing pottery, and an occasional intermural burial (for pottery types of the BMAC see Udeumuradov, 1993; 2002). Four superimposed levels of architecture were recovered with an earlier underlying "eneolithic" settlement, radiocarbon dated to the first half of the third millennium. What distinguishes Adji Kui 1 from 9 is the presence of a large fort (qala) within the center of the equally well fortified settlement (Fig. 15a-b). The excavator refers to this formidable qala as a "caravanserai". The presence of a fortified "farm" distinguished from a qala is well demonstrated in the ethnographic context (for illustrations of distinctions of farm and qala in the $19^{\text {th }}$ century see Szabo and Barfield, 1991: 164, 188). Sarianidi refers to similar structures as a "temple" or "palace". I have suggested the term qala, on ethnoarchaeological grounds, to designate the residence of a local khan (Lamberg-Karlovsky, 1994). Thus, the settlement of Adji Kui 9 parallels that which we know from Gonur and Togolok: a heavily fortified settlement, with square or round bastions, containing a significant fortified 'qala' 


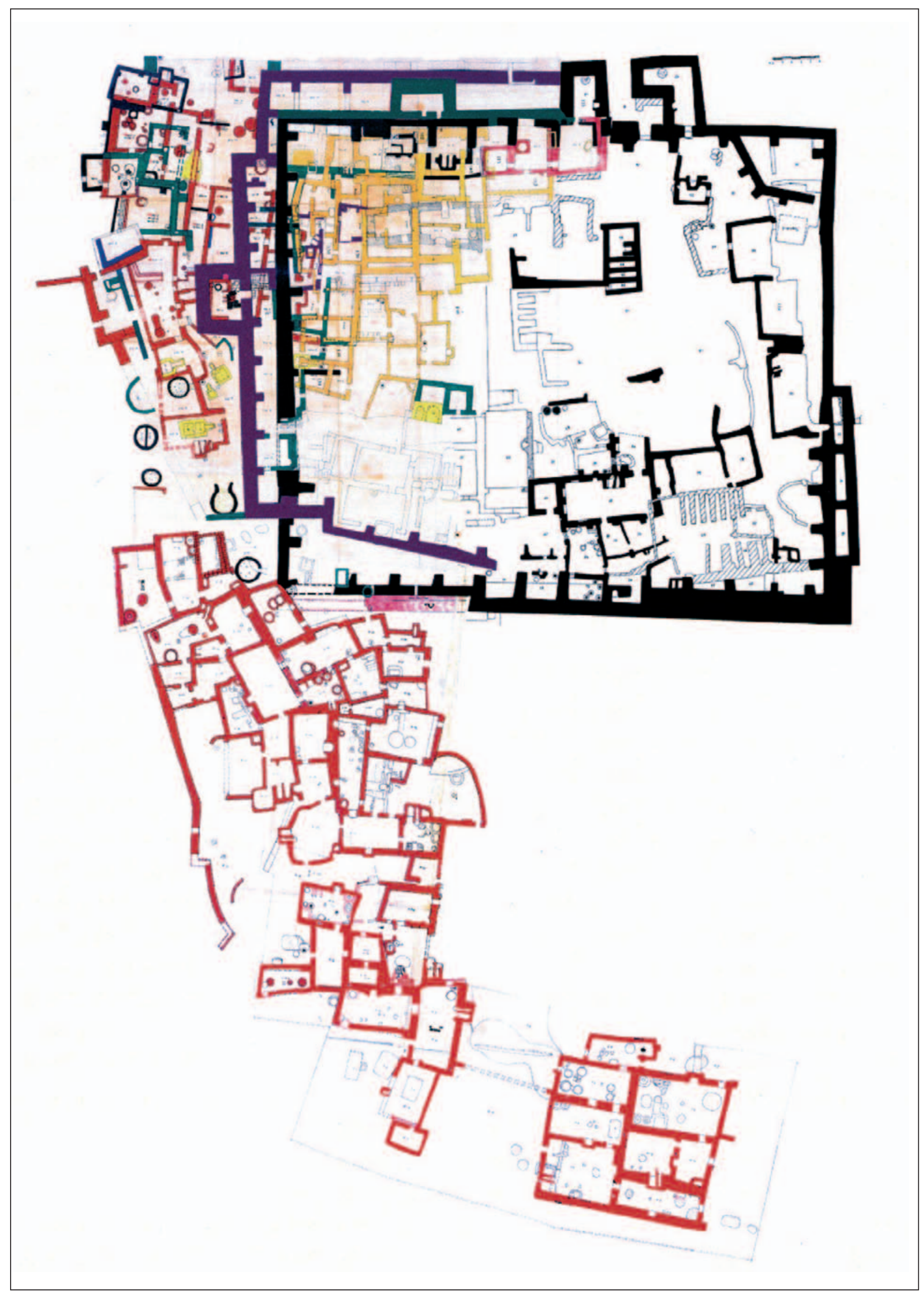

Figure 14a. Excavations at Adji-Kui 9,

"the farm" (Courtesy G. Rossi Osmida). 


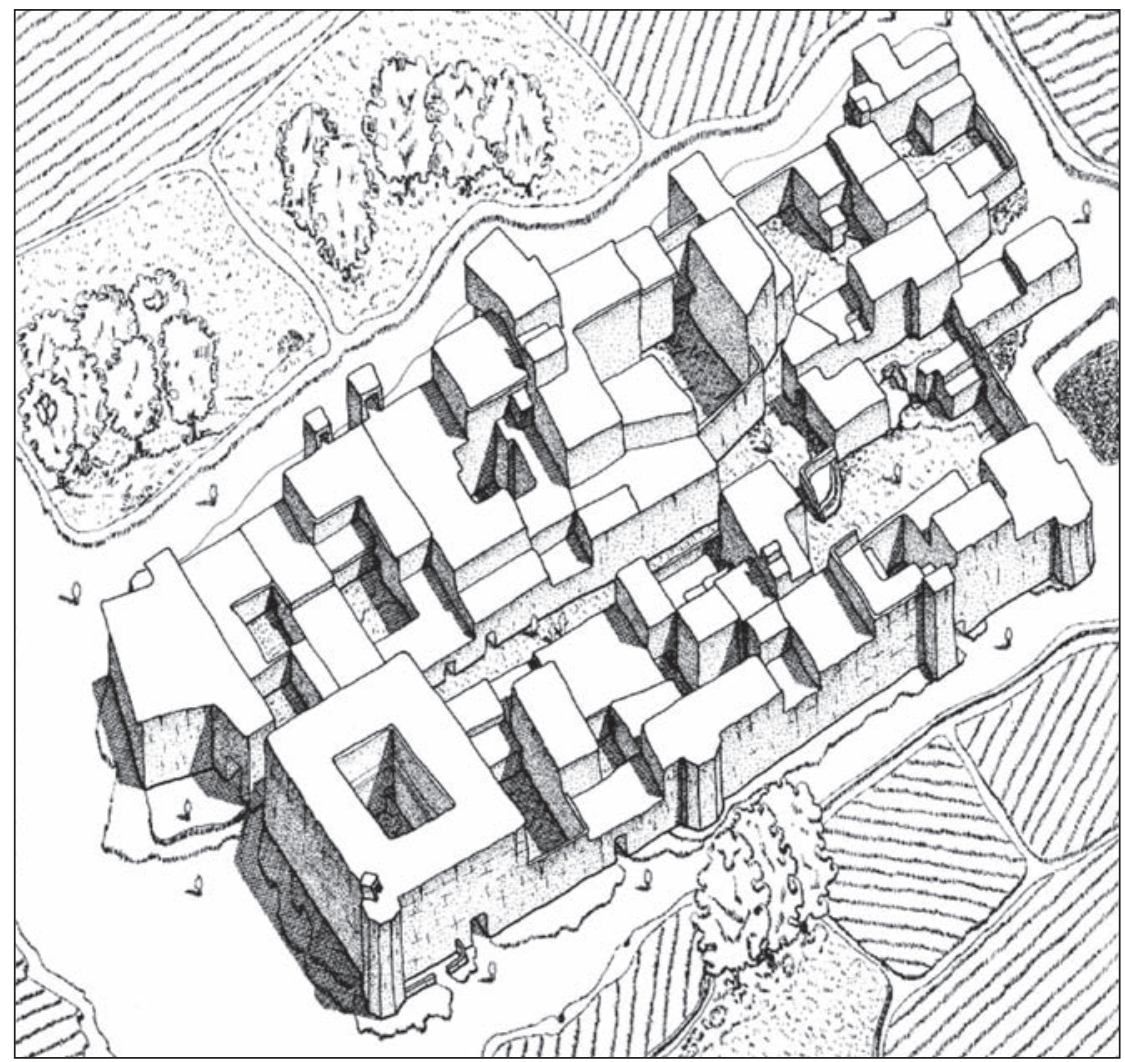

Figure 14b. Adji-Kui 9, "the farm" (Barfield, 2010: 188).

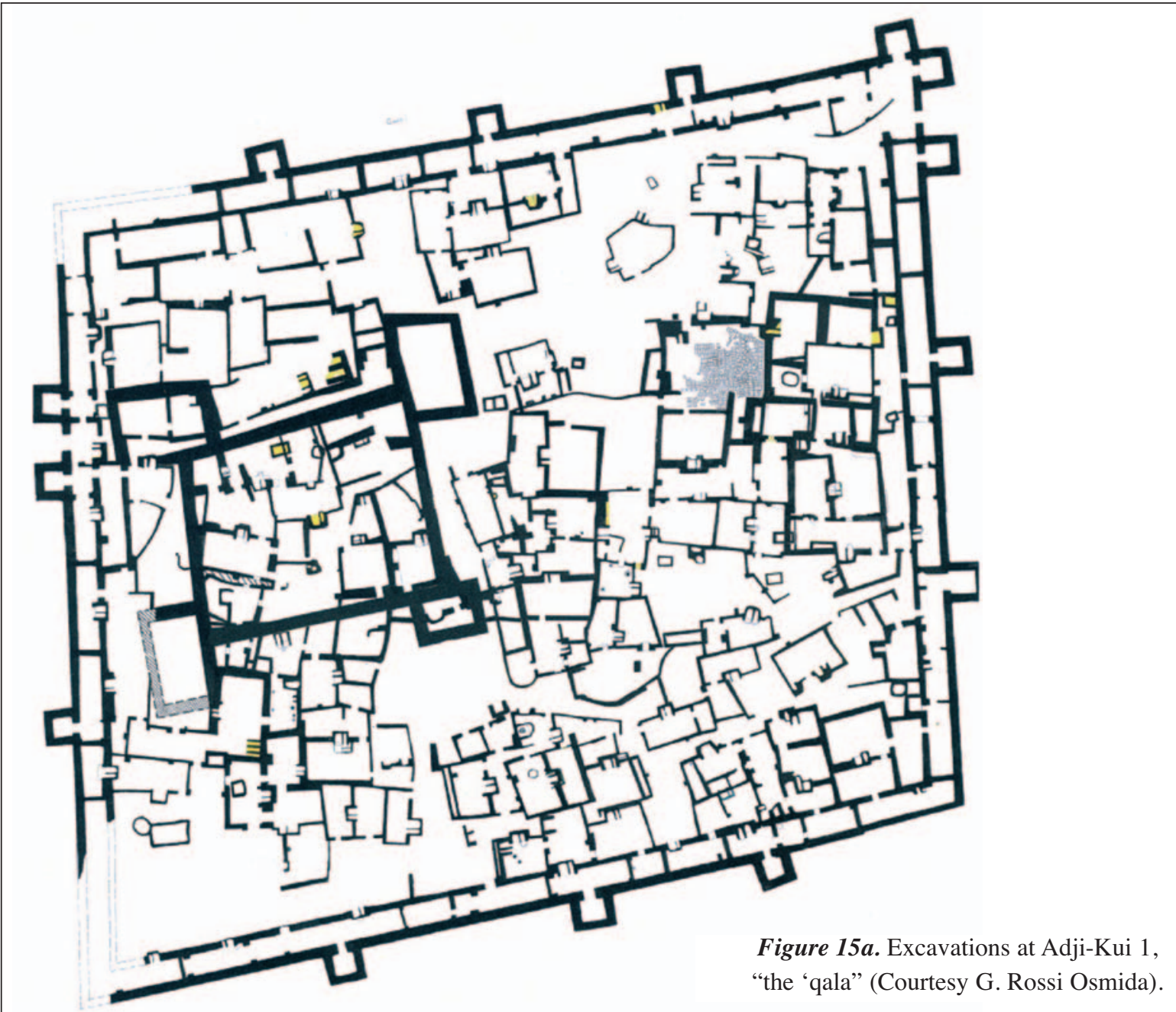




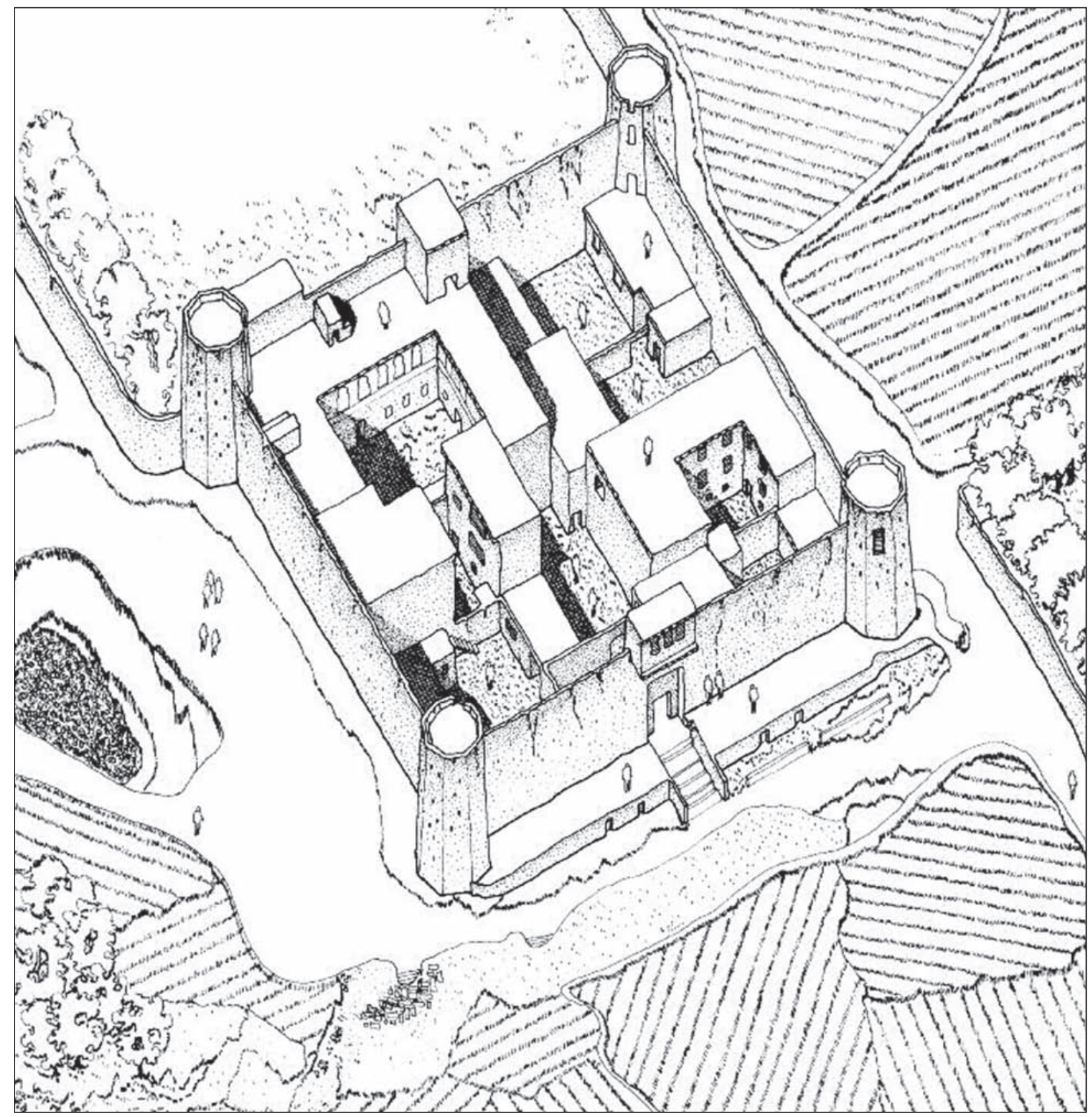

Figure 15b. Adji-Kui 1, "the "qala" (Barfield, 2010: 163).

within the fortified community. The distance between Adji Kui 1 and 9 is less than $2 \mathrm{~km}$. A cemetery between the two settlements has been excavated and was doubtlessly shared by both communities. The total size of the communities can be determined only through excavation but based on sherd scatter a figure in excess of 10 hectares is assured. The presence of a "fort", "palace", temple" or "qala" at Adji Kui 9 and a "farm" at Adji Kui 1 suggests that the former housed the local authority while the latter, was inhabited by a related community devoted to agricultural production.
The significant differences between the two communities architecture, the proximity of a shared cemetery, and the first identification of an 'eneolithic' settlement in the Murghab delta have significant import. Based on the results of his stratigraphic excavations, and radiocarbon chronology, Gabriele Rossi Osmida suggests a continuous sequence of settlement at Adji Kui 1 from $2800 / 2700$ B.C. to $1800 / 1700$ B.C. (Fig. 16). His is an unequivocal support for the indigenous development of the Oxus Civilization while distancing the BMAC from the fantasies of an Aryan, Zoroastrian and Vedic world of migrants from Anatolia. 


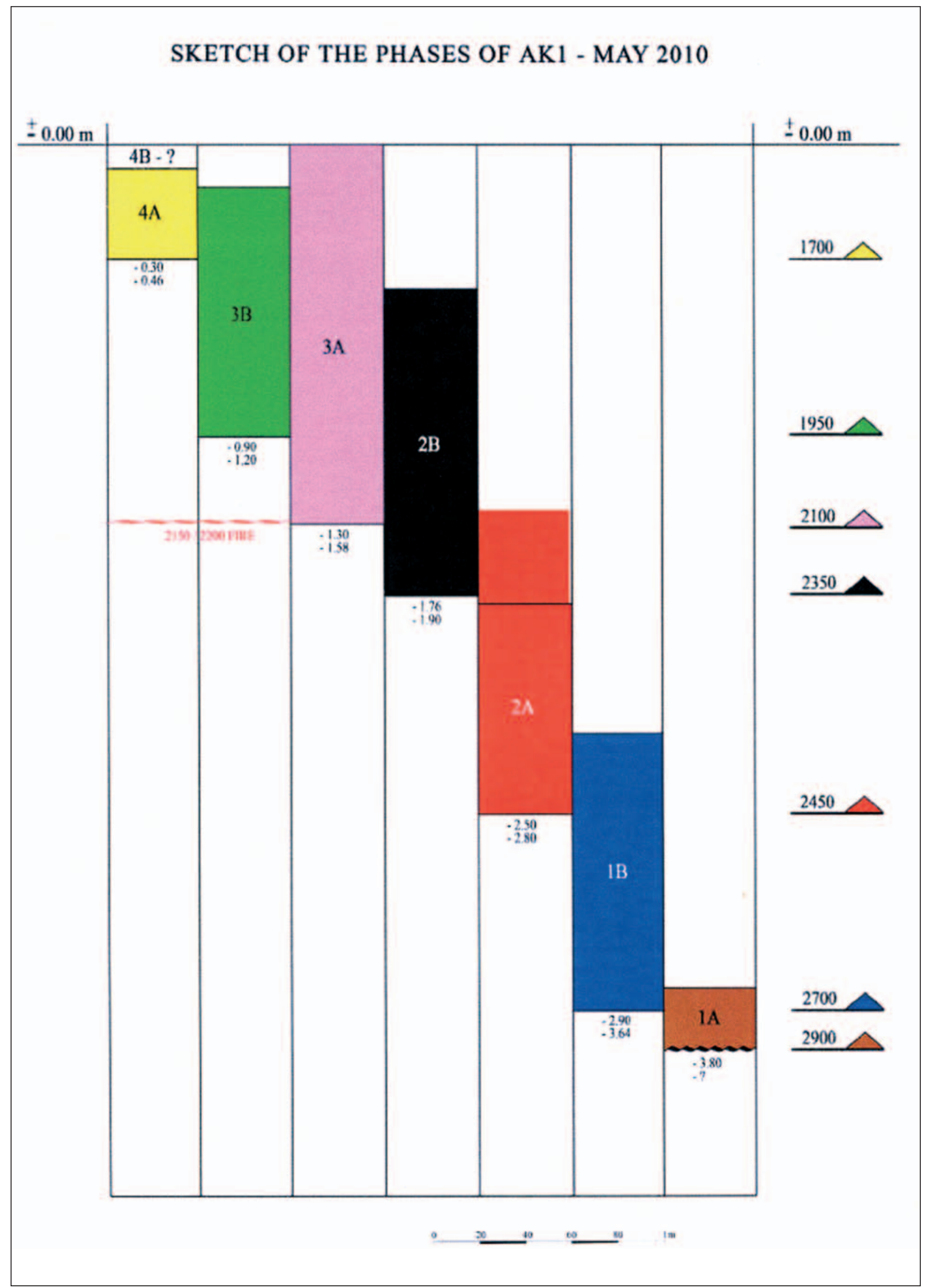

Figure 16. Chronological Periods of Adji-Kui 1 (Courtesy G. Rossi Osmida). 
What may be said of the culture of the Oxus Civilization? Its material culture is sui generis while its aesthetic products and technological achievements are the equal of any Bronze Age community in the Near East. Its fortification systems are more impressive than any within the contemporary Bronze Age of the Near East. Artifacts of the BMAC are found on numerous sites from Susa to Mohenjodaro (Amiet, 1986; Possehl, 2004; Ratnagar, 2004), and the Persian Gulf/Arabian Peninsula (Potts, 2008). Gregory Possehl (2004) has recently coined the term "The Middle Asian Interaction Sphere" (MAIS) to capture the extensive relations that characterized the north-south interaction involving the BMAC, the Indus Valley, the Iranian Plateau and Arabian Peninsula. Unfortunately, this restrictive term narrows the extent of interaction that characterized the Bronze Age of Asia. The constituents of that termed MAIS (Central Asia, the Eurasian steppes, the Indus Valley, Persian Gulf, and the Iranian Plateau) had extensive relations, political and economic, with Mesopotamia, which in turn, had continuous interactions throughout the Bronze Age with the eastern Mediterranean. The nature of this expansive interaction, at different times and in different places, involved conflict, political alliances, gift exchange, trade, and even open markets (Salvatori, 2008a; Lamberg-Karlovsky, 2009; 2013). The interactive world of MAIS was part of a far greater world of communication extending from the Aegean to China and involving a down-the-line chain of interaction.

The Oasis environment of the BMAC in which specific oases are connected by both natural and constructed canals begs the question as to the nature of the administration of water. Given the arid environment, the scarcity of water, the population density of numerous urban centers and the absolute dependency on irrigation for agricultural production, it is hard to conceive of the allocation and administration of water, dams, sluice gates, fish weirs, and reservoirs (as evident at Gonur) not being under a regional central authority. Ethnohistorical information from Central Asia, both environmental and cultural, inform us that fortification systems, the control of irrigation networks, and regional conflict are all co-occurring phenomenon. Nineteenth century ethnohistorical data, involving these three factors, are complimented by comparable evidence derived from the Iron Age, Bronze Age and Medieval Period by the decades long research program of the
Khorezmian Project (Tolstov, 1948 for summary volume).

The importance of irrigation in Central Asia is a leit motif of all authors, whether concerned with antiquity or recent times. The principal city along the Murghab River was, from the Iron Age to modern times, Merv. It was visited by Alexander the Great, ruled by his successor Antiochus Nicator, and during Sassanian times it was the seat of a Nestorian archbishop. On February $25^{\text {th }}$ 1221 the Mongols, under the leadership of Genghis Khan, destroyed the irrigation networks and are said to have killed 700,000 residents of the city. Contemporary texts all attest to the irrigation systems as the lifeline of the communities. In 1784 The Emir of Bukhara broke the great dam of Merv "which filled the numerous canals and fertilized the whole country, in the hope of rendering it a desert". For decades after the destruction of Merv, and its surrounding countryside, the region was reduced to "about 100 mud huts" (Stewart, 1881: 535-536). By 1840 Lt. Col. G.E. Stewart observed that "During the misrule and anarchy of the past 60 years the ancient dam of the Murghab was neglected and carried away. The dam is again set up and the lands brought under culture"

Although, one does not wish to support Karl Wittfogel's (1963) "Irrigation Hypothesis" in which the centralized control of water resources leads to the emergence of a pristine despotic state, it should be obvious that irrigation dictates choices for settlement, colonization and urbanization. It also exposes dependents to natural calamities, i.e. reduced rainfall, siltation, flooding, as well as humanly induced conflicts for the control of a limited resource. It becomes equally obvious that even before a settlement density is achieved and reaches its carrying capacity that regional center(s) of authority will emerge to administer the limited water resource. Efforts to extend the limits of resource exploitation by grabbing more land and/or water brought forth challenges to authority. In the past such challenges were exercised by specific lineages whose elite were considered as having the exclusive right to rule (Vambery, 1865: 378-412; Sneath, 2007; Barfield, 2010 71-76).

The BMAC would appear to contain a material culture, technological achievements, and a settlement density that can be compared to Mesopotamia. The sole significant difference is the absence of writing. However, geometric 
tokens with incised signs, sealed bullae (Fig. 17ab) and a single sherd with several inscribed glyphs, allegedly containing linear Elamite script, have been recovered and support the presence of nascent forms of administration (Sarianidi, 1998: 88, fig. 41; 2002: 195; Klotchkov, 1998). Giuseppe Viscato (2000: 243) reminds us that an administrative bureaucracy in Mesopotamia could be a notable burden: "The maintenance of such a large and expanding bureaucracy may have become, at particular moments in history, an intolerable burden. We can, in fact, observe that the major collapses of Mesopotamian society in the third millennium, in the E.D. IIIa, the Sargonic, and Ur III, and perhaps the Late Uruk period, all coincide with the maximum production of tablets and the highest number of scribes".

The Oxus Civilization is arguably the most important, and uniquely so, civilization to be discovered in the second half of the $20^{\text {th }}$ century. Its extensive contacts with distant neighbors, its exceptional adaptation to an oases environment, the problematic understanding of its 'rise and

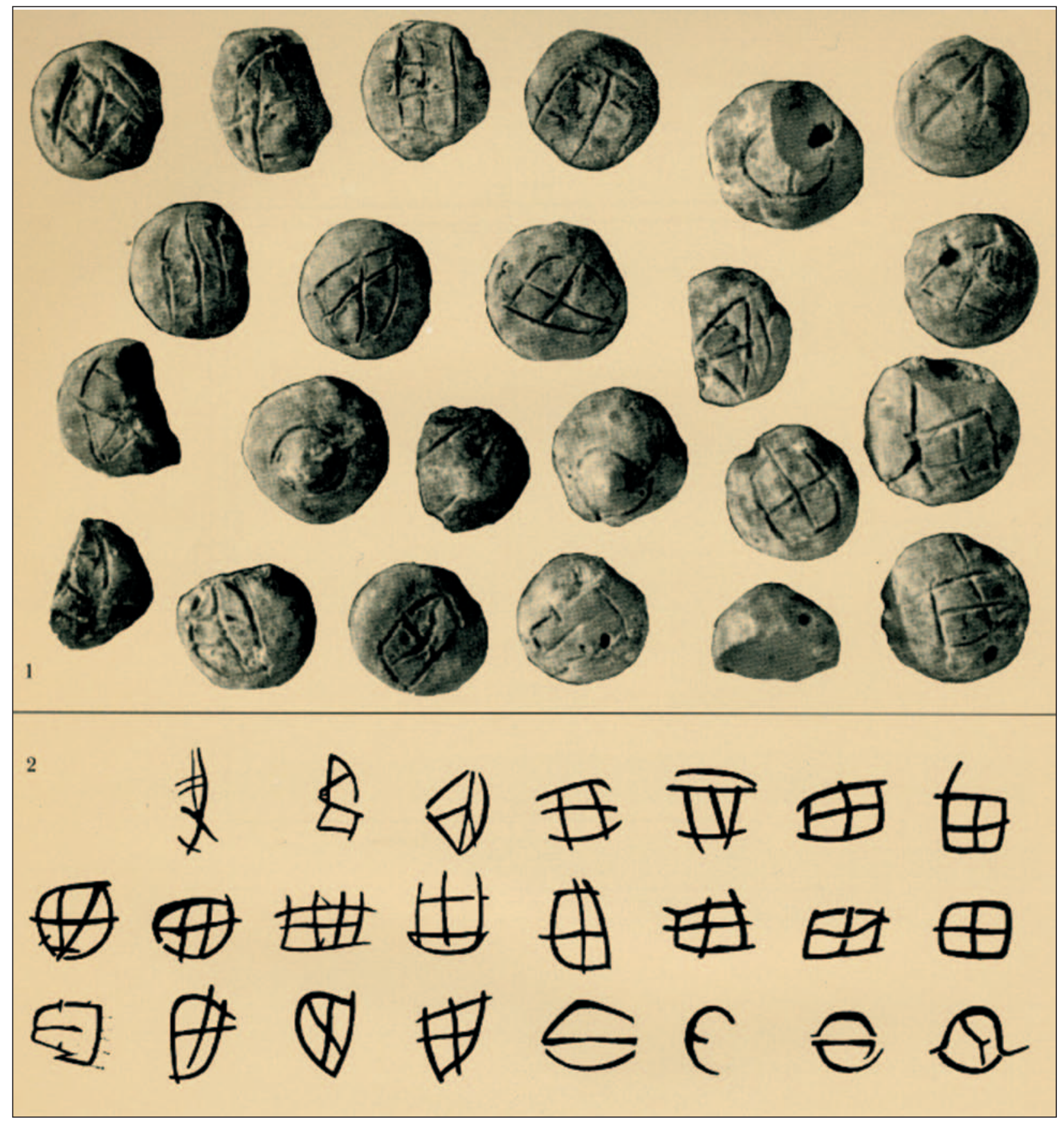

Figures 17a. "Tokens" with their "signs" from Gonur depe (Sarianidi, 1998: 88 fig. 41). 

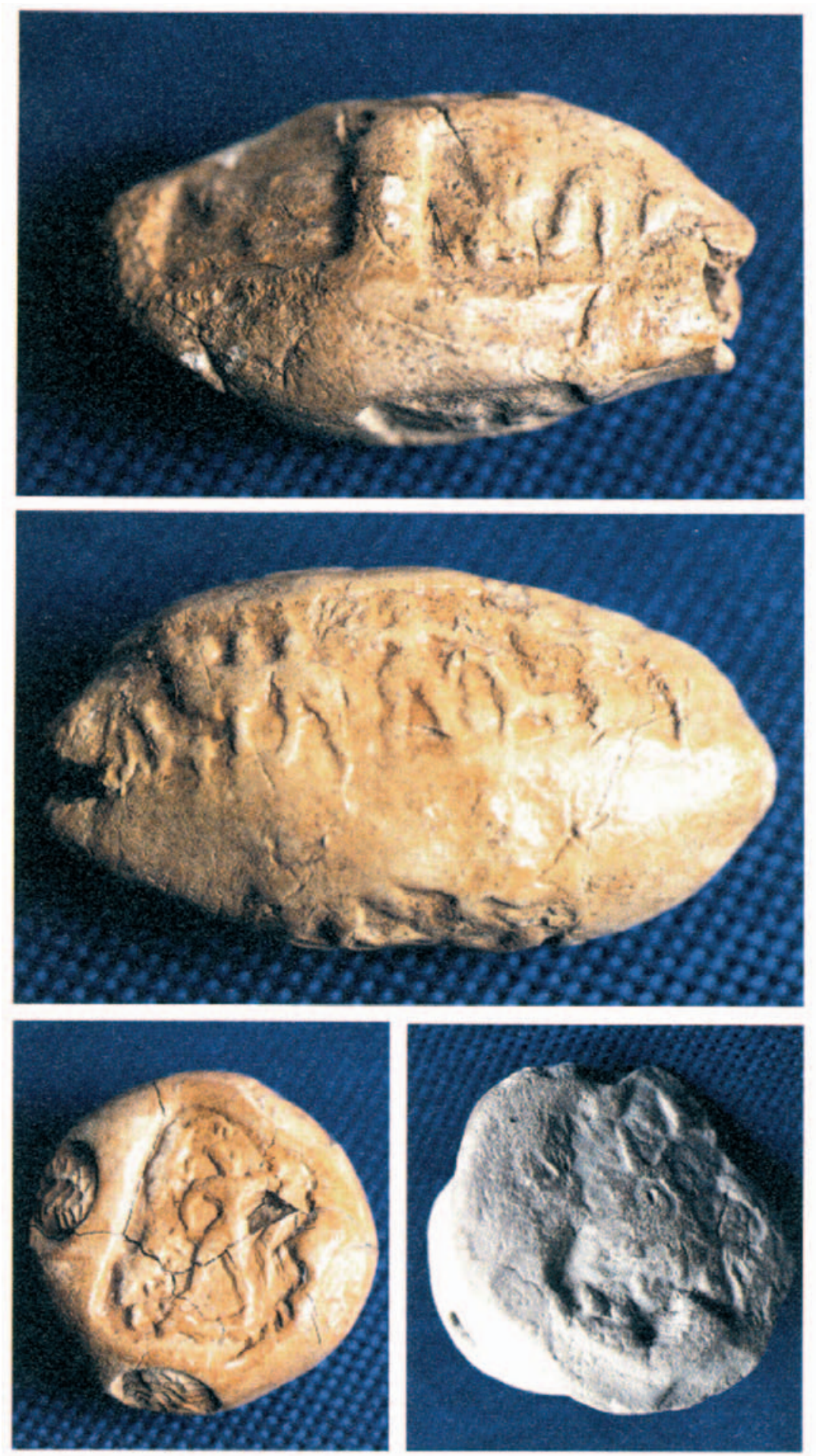

Figures 17b. Sealing on Bullae from Gonur depe (Sarianidi, 2002: 195).

fall', its signature architecture of monumental structures and fortification systems and its complex irrigation networks add to our roster of civilizations a new phenomenon - one in need of both understanding and exposure to the comparative approach (Fig. 18a-i). Surprisingly, the Oxus Civilization is all but ignored in the synthetic literature. A description detailing its nature has not appeared, even as a cursory summary, within a single textbook or general work, concerning the Bronze Age Civilizations of the Old World (but see the useful summary dealing with Eurasia by Kohl, 2007). 


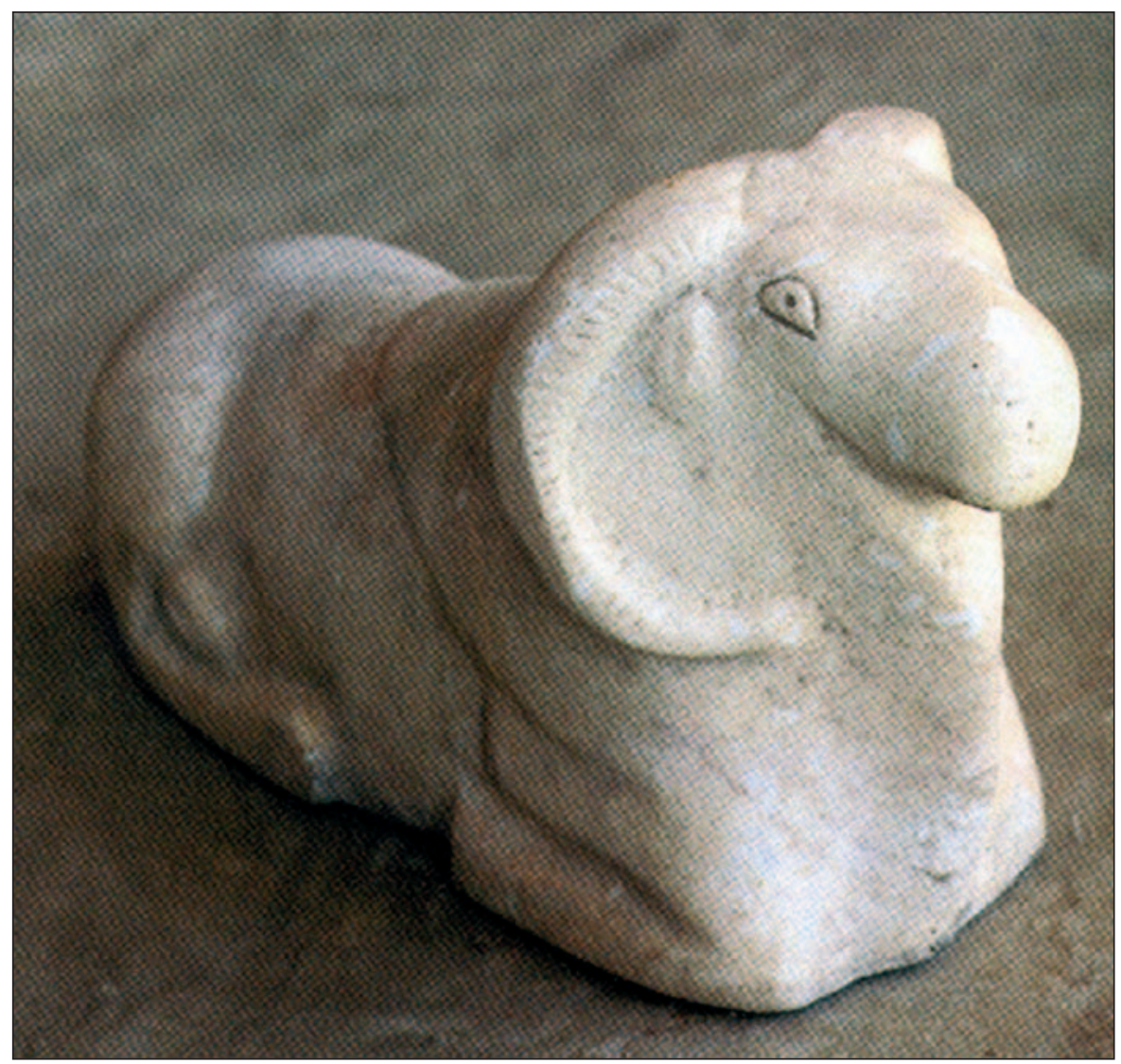

Figure 18a. Stone statue of a ram from Tomb 3220, Gonur depe (Sarianidi, 2009: 196 fig. 108).

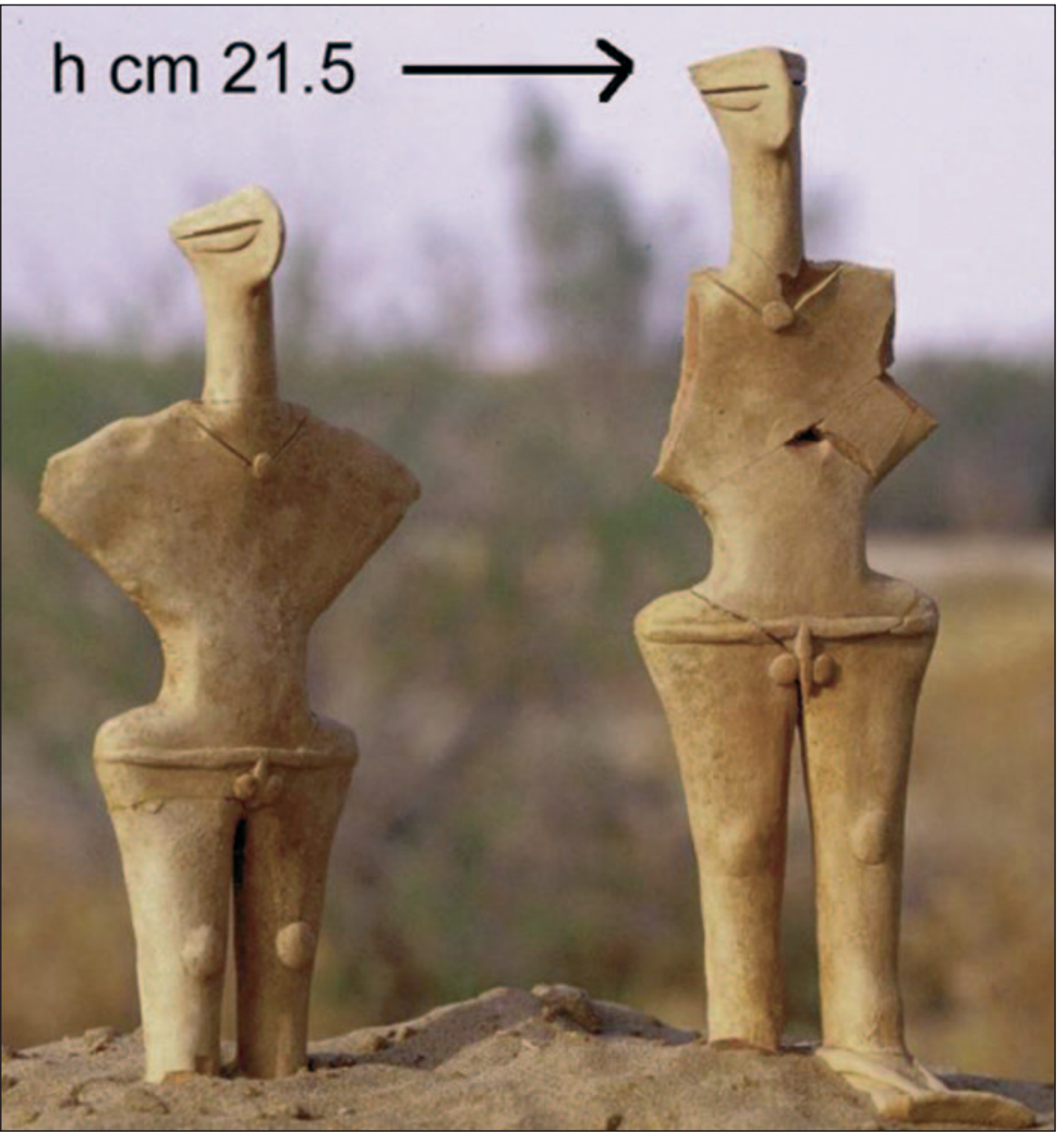

Figures 18b. Clay figurines from Adji Kui 9 (Courtesy G. Rossi Osmida). 


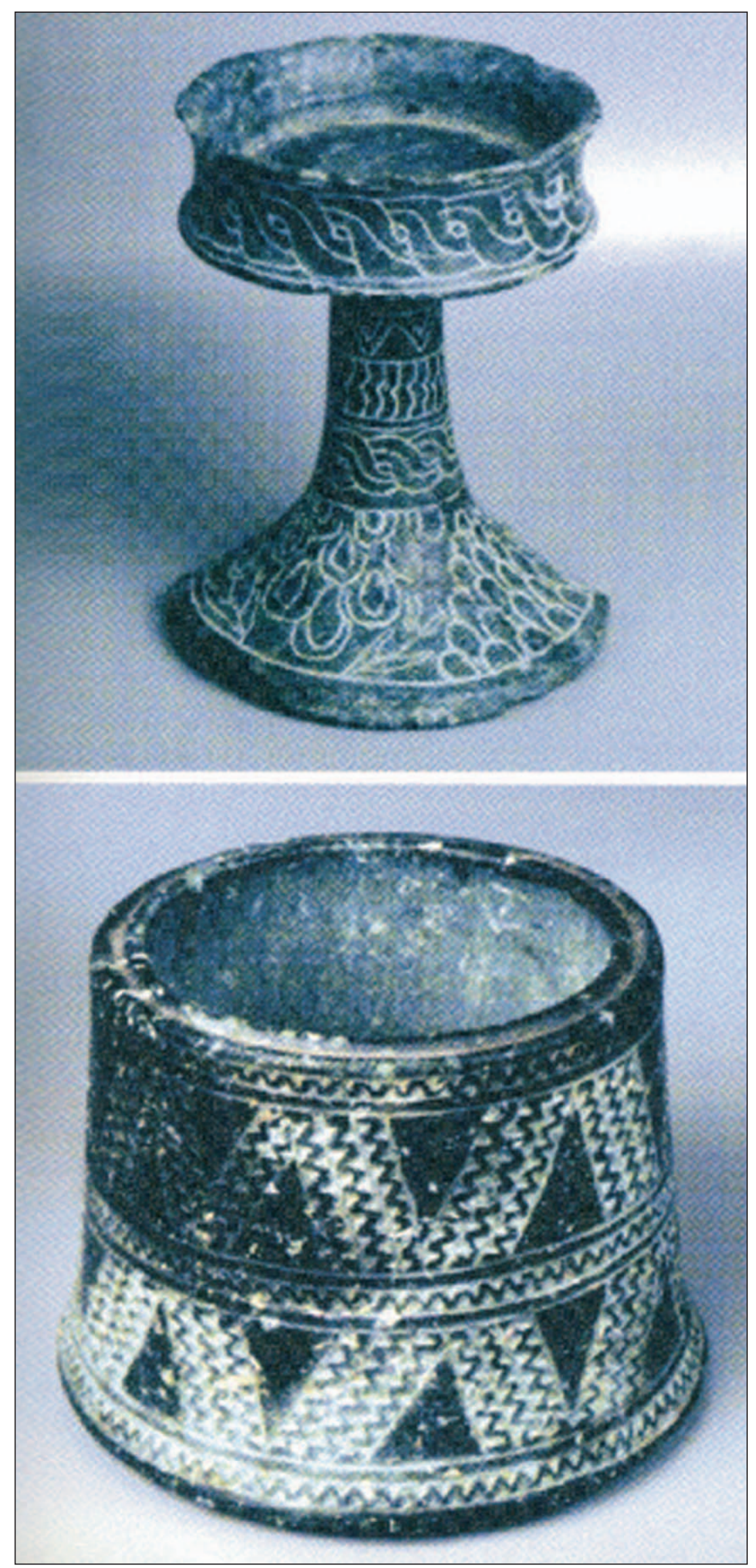

Figures 18c. Chlorite vessels from Gonur depe (Sarianidi, 2002: 131). 


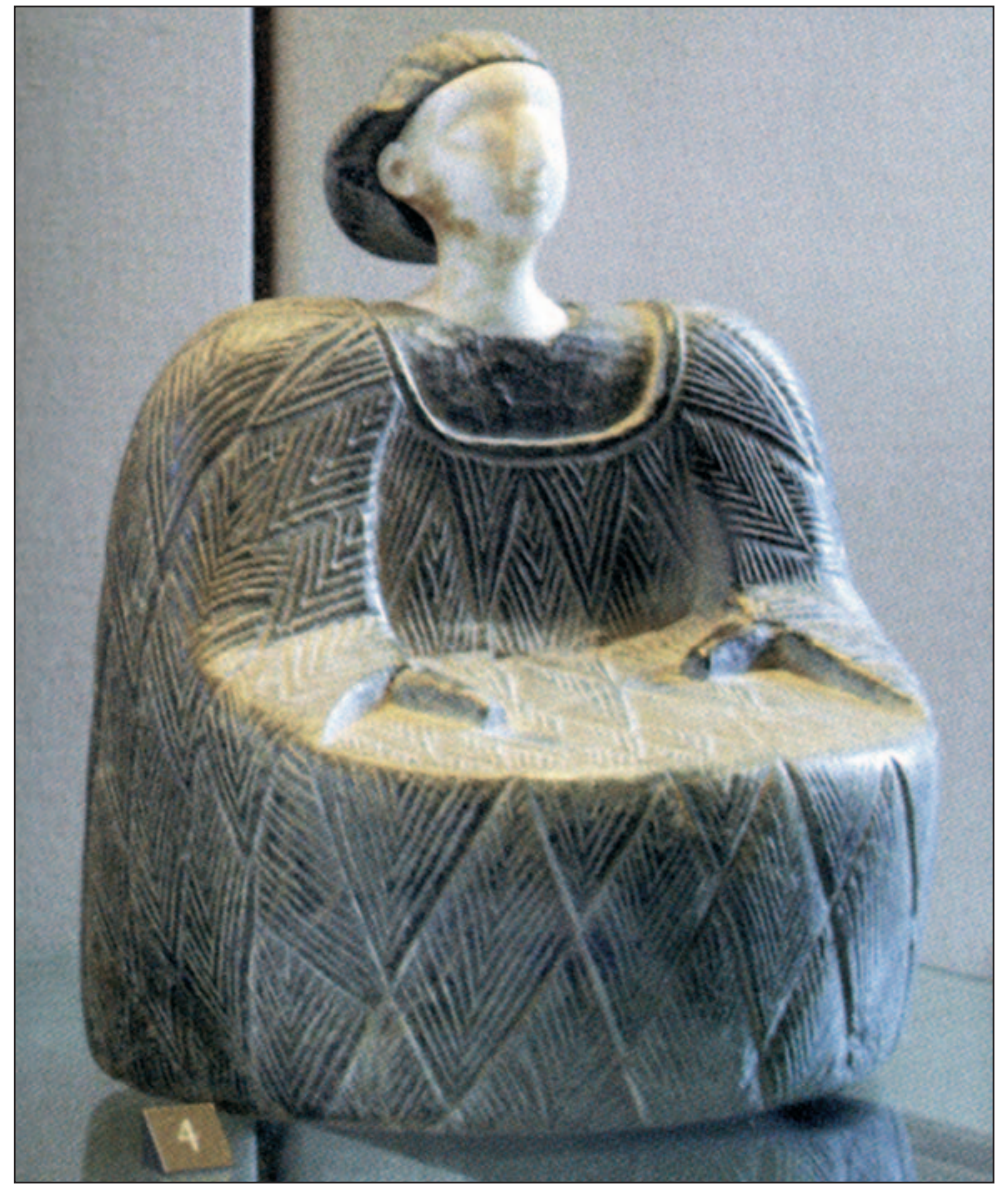

Figure 18d.Compound stone statue from Gonur depe (Sarianidi, 2009: 115, fig. 43).

Figure 18e. Clay figurine with bronze earring from Gonur depe. Margus 2002 (Sarianidi, 2002: 297).

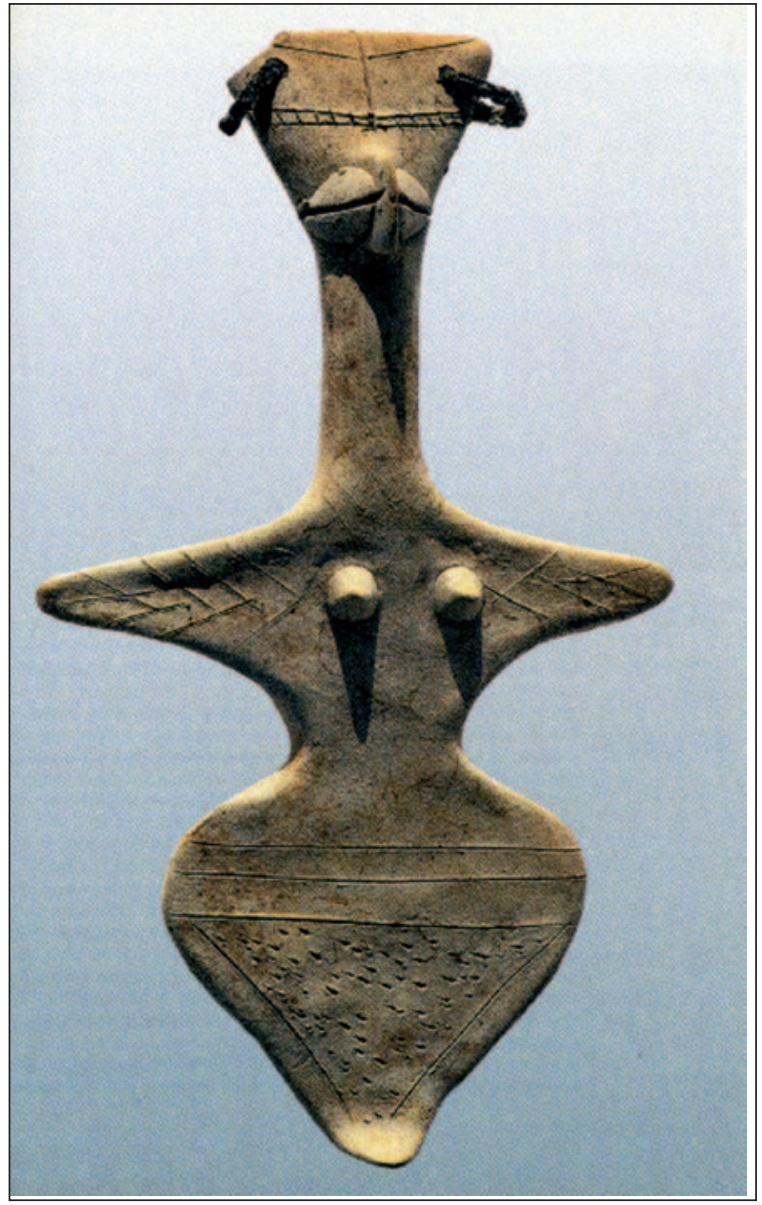




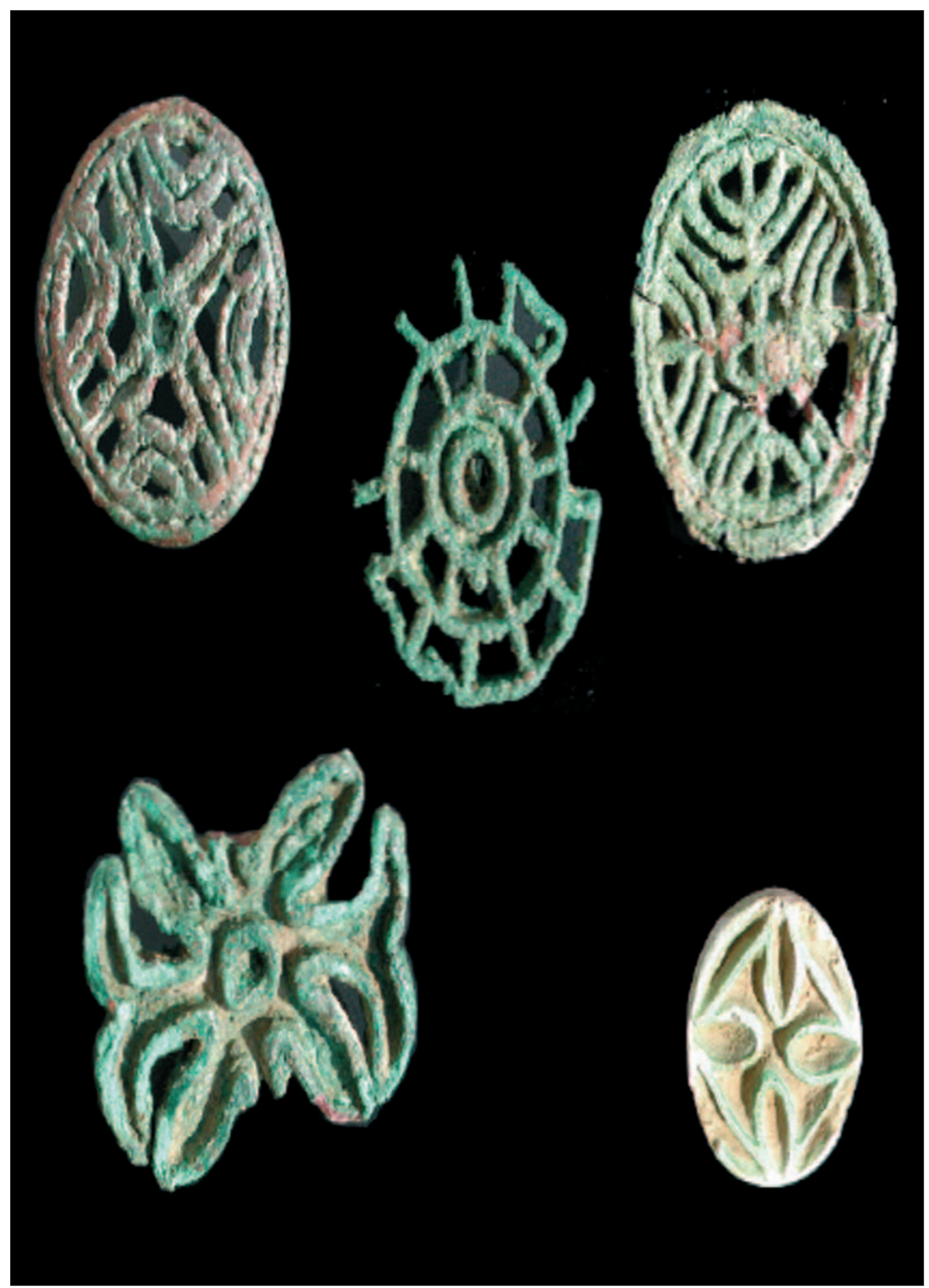

Figures 18f. Bronze seals from Gonur depe. Margus 2002 (Courtesy G. Rossi Osmida) 


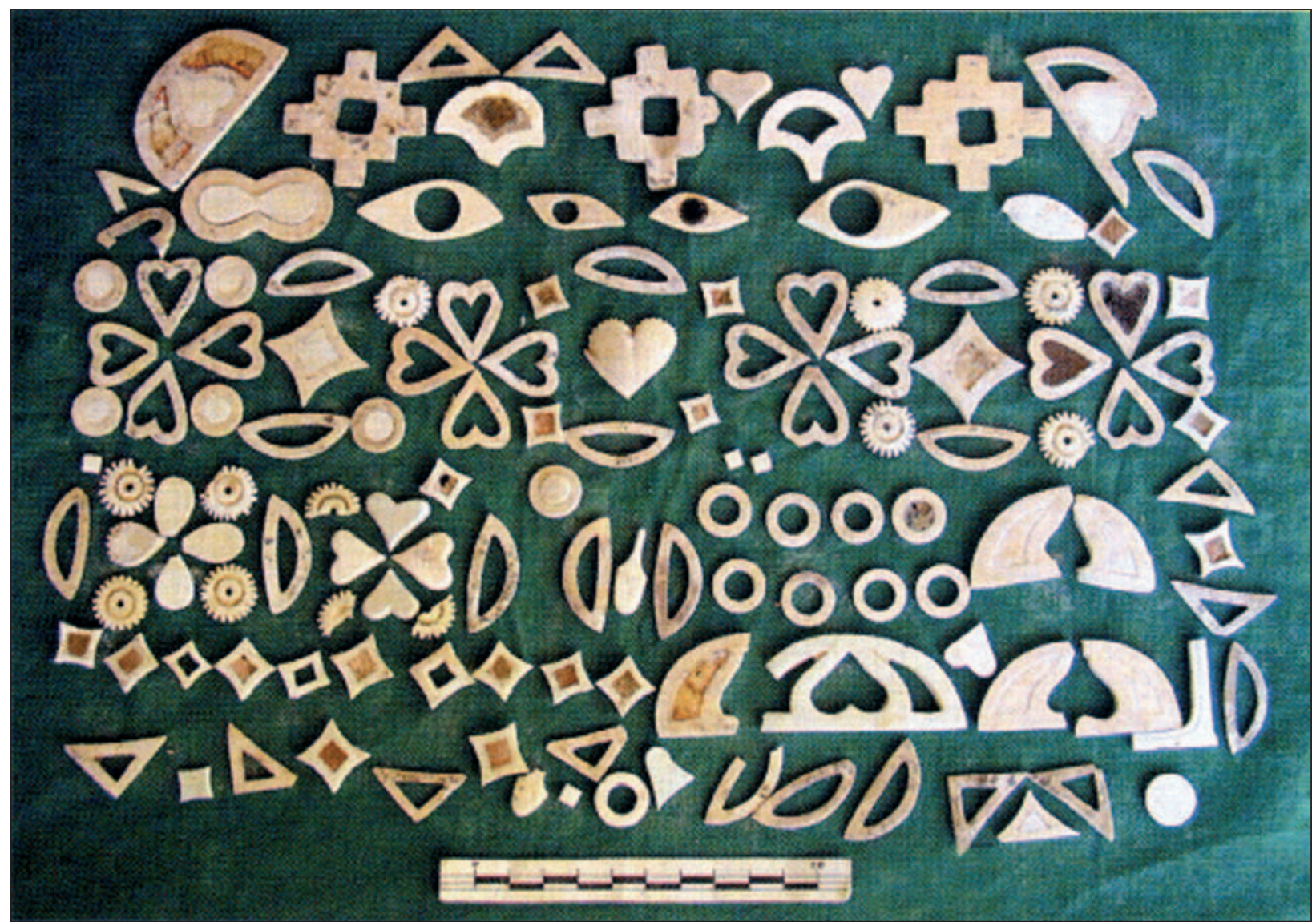

Figures 18g. Ivory mosaics from Room 3235. Margus 2002 (Courtesy G. Rossi Osmida).

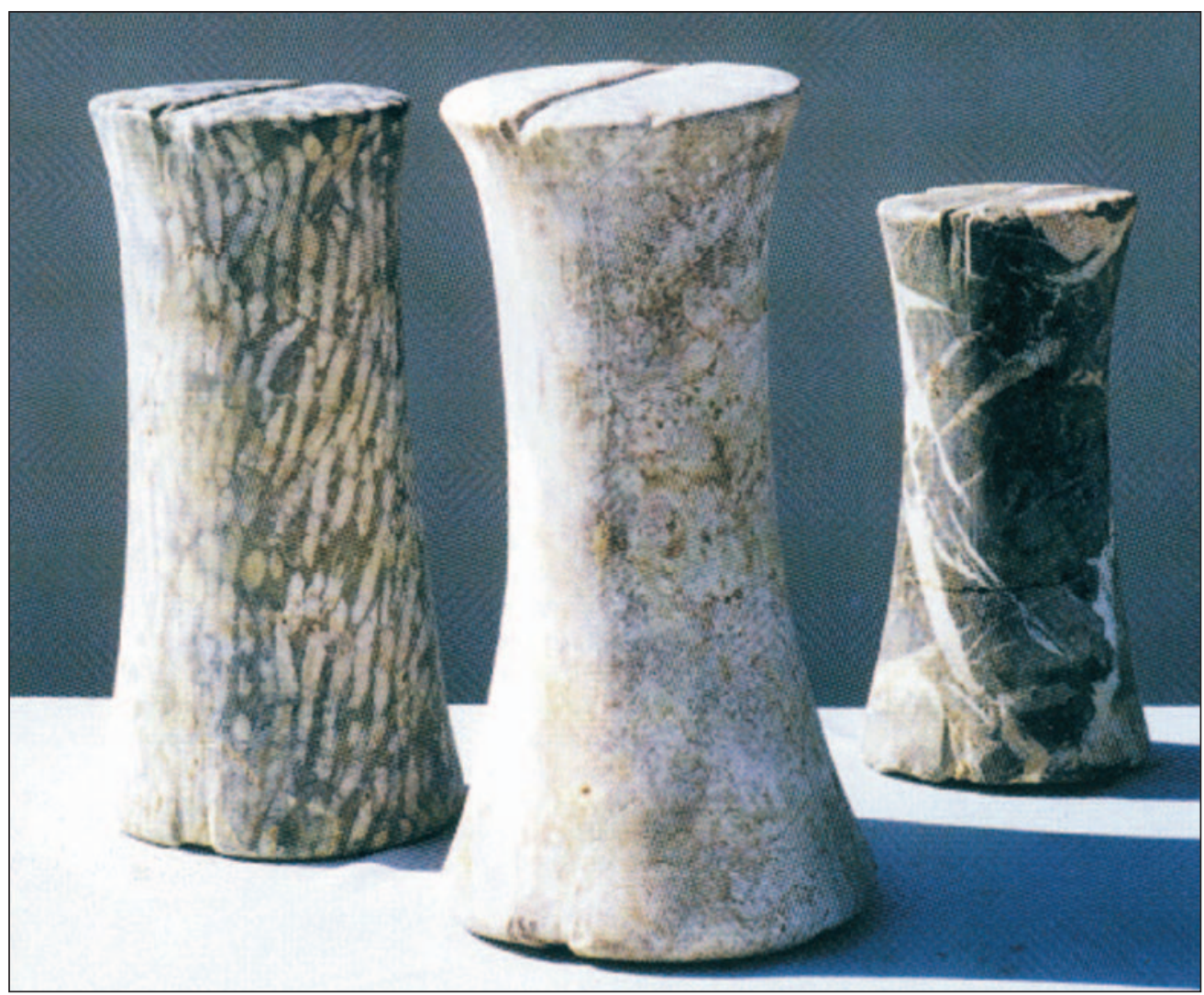

Figures 18h. Stone columns from Gonur Necropolis. Margus 2009 (Courtesy G. Rossi Osmida). 


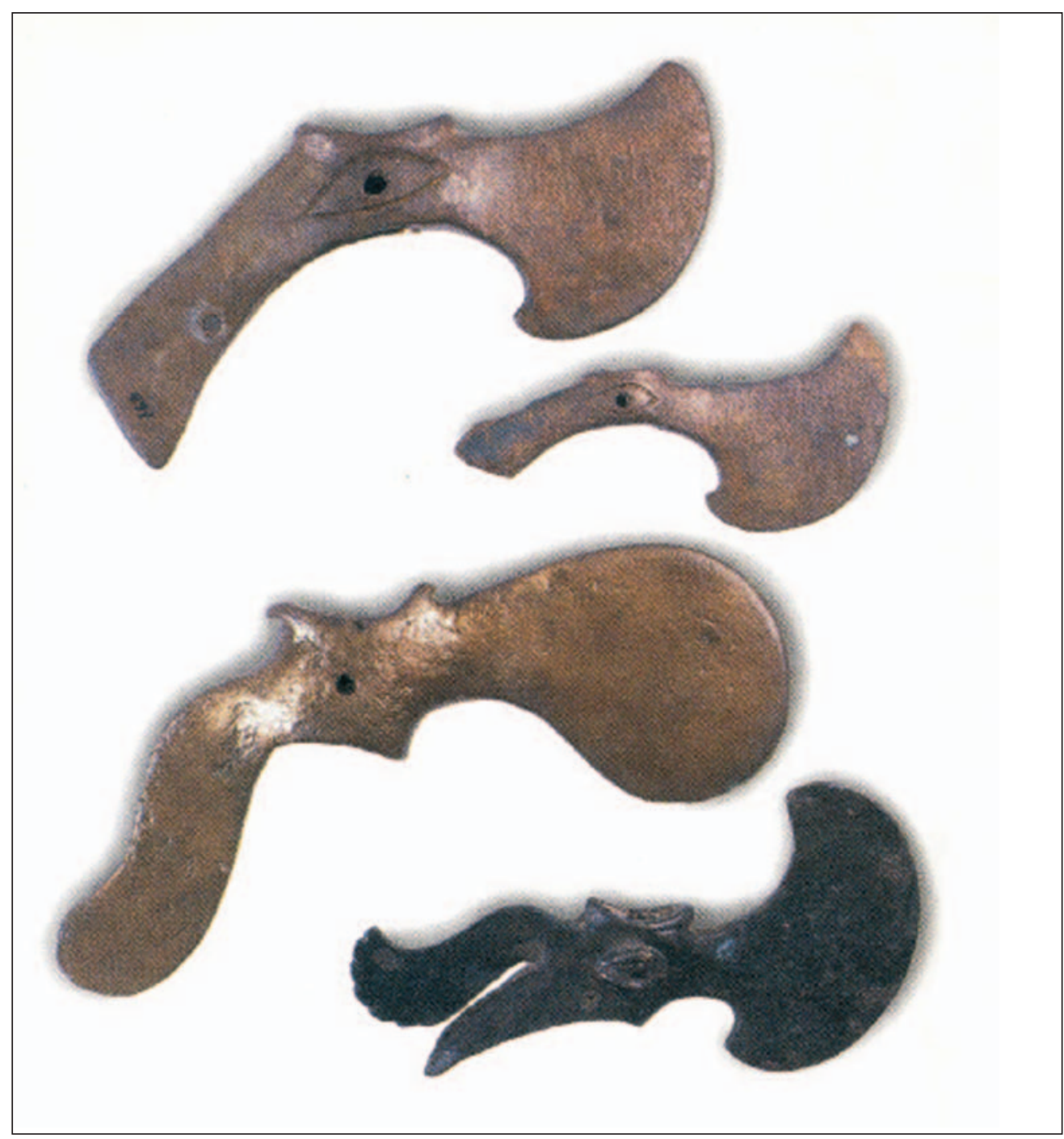

Figures 18i. Bronze axes from Gonur Necropolis. Margus 2009 (Sarianidi, 2002: 102).

\section{DISCUSSION}

Although little known, and even less discussed, the BMAC deserves a central place in discussions detailing the comparative nature of Bronze Age civilizations. It is to this concern we turn. Throughout antiquity landownership, or control, was the criterion, the determinant of a person's social status. Land supported self, family and clients. Its harvest offered taxes, while its capital allowed for loans, credit and debt. Surplus land could be rented out on a sharecropping basis allowing for an accumulation of wealth. Within the BMAC land was abundant, water was scarce. Access to water was the key to efficient and productive farming while irrigation technology was the key to its distribution. The Central Asian water regime is unique. Unlike the major rivers of the world that debauch into bodies of water those of Central Asia empty into the desert. These major rivers, as that of the Murghab River which nourishes the BMAC, form alluvial fans as they empty into the desert. The dendritic network of the deltaic fan affords numerous opportunities for agriculture within the fingered network of rivers emptying into the desert. They also afford an opportunity for building a grid of constructed canals to form an integrated irrigation network throughout the deltaic fan. I do not wish to reopen Wittfogel's (1963) 'irrigation hypothesis' in which irrigation, as already mentioned, is 'causal' to the formation of a 'despotic state'. I do mean to point out however, what has long been held as self evident within the Central Asian world, whether for antiquity or more modern times, that irrigation was absolutely central to the emergence and sustainability of urbanization and 
cultural complexity! (Schuyler, 1874; Andrianov, 1960; Mohammedjanov, 1975). Throughout the history of Central Asia the opportunities offered the individual, or the group/tribe, involved the construction of irrigation networks, and the control of its water. The control of water was central to the development of power relations within regions and groups. Historically the network of irrigation canals that tied BMAC sites into an ecological unity occurred within a diversity of power relations. A cyclical pattern of centripetal vs. centrifugal forces, regional vs. centralized control, was always at play. The fact that each and every settlement within the BMAC was fortified attests to a sustained conflict over resources. The principle and essential resources for sustaining the considerable population was land and water

The pervasive tendency to focus upon first order effects results in irrigation being subordinated to urbanization and the emergence of centralized political control. The presence of irrigation is perceived as a secondary order effect. This view finds its origins in the 1960s with the vehement opposition to Wittfogel's "irrigation hypothesis" as well as to the pioneering research on the role of irrigation derived from the modern ethnographic and archaeological record (Fernea, 1970; Adams, 1966: 66-71, 1981; Hunt, 1976) in which irrigation was said to precede cultural complexity and thus had little to do with its emergence. Such a view tends to overlook the fact that technological innovation may have long term and even unforeseen consequences disproportionate to their immediate significance. Eliminating irrigation as a 'causal' factor in the emergence of cultural complexity succumbs to the fallacy of overlooking the "law of secondary consequences', i.e. where an initial cause is of little consequence compared to its ultimate impact. Ignoring technologies that gain complexity and significance through time comes at a price of ignoring its slow cumulative impact. I submit that in the absence of irrigation the BMAC, and all subsequent Central Asian Khanates of the $19^{\text {th }}$ century could not have existed. Similarly, could the Mesopotamian empires of the Ur III, Sasanian and Abbasid have been able to support themselves in the absence of the irrigation networks that allowed for a surplus agricultural production? Irrigation permits surplus production of agricultural products that, in turn, allow for the slow cumulative emergence of an ever increasing cultural complexity.
Irrigation required alliances, cooperation and competition between different city-states, tribes, lineages, and, at the local level, between extended families, allowing for the dissemination, control, and maintenance of the water supply.

Was the BMAC a single 'state', a hegemonic power controlled by a bureaucracy led by a single person? Or was it a tribal chieftainship of constant tension over land, water, and a diversity of contending tribes? Archaeological evidence of the BMAC settlement regime, in which fortified settlements were situated every $50 \mathrm{~km}$, the classical and medieval texts, and an extensive library of ethnographic and travel literature, written over the course of the last four centuries, all argue for the presence of local khans presiding over tribal contexts (for relevant descriptions of the primordial tribal world of Central Asia see the essays in Cummings, 1977). The extensive excavations at Gonur, its monumental fortification systems surrounding the community, the large central qala, its wealth placed in the cemeteries referred to as "royal", suggest that the site was a major political center presided over by a great khan. Other sites, of comparable size but with less extensive excavation, i.e. Togolok, Djarkutan, Adji Kui 9, attest to a diversity of political powers likely presiding over distinctive tribes. I would suggest that the BMAC political structure was one referred to as 'tanistry', representing an election, by tumultuary consent, of a khan selected by a convocation of tribal chieftains. The absence of a clearly defined dynastic tradition, or formal rules of succession, often led to what is called "bloody tanistry", that is, a murderous competition following the death of a khan between contenders from specific descent groups that alone had the right to compete for power. This form of tribal rule, which our political rulers of the modern world would do well to understand, characterized Central Asia for millennia and still accounts for the political system of $19^{\text {th }} / 20^{\text {th }}$ century Afghanistan (Barfield, 2010: 78). The BMAC appears to conform to what Thomas Barfield calls a "Turko-Persian" tribal society, one characterized by a social hierarchy "organized through ranked set of lineages, clans, and tribes in which leadership was hereditary and limited to specific descent groups. This tradition produced tribal confederations an order of magnitude larger than egalitarian ones (i.e. the Bedouins of Arabia (...) under the rule of a single leader". Such hierarchically structured confederation of militant tribes 
could reach populations in the hundreds of thousands, as with the Mongols led by Genghis Khan or the Pashtun of Afghanistan led by Abdul Rahman. Warfare and conquest was the result of competition among rival elites, often relatives from different lineages of the same tribe. This type of state, if such it is, is perceived as the property of the ruling elite. The distinction between tribes that are 'egalitarian' (tribal republicanism) and 'hierarchical', (royal pretensions) must make way for the existence of both structures within a single tribal entity. Such is true today among the Pashtun of Afghanistan. In the $19^{\text {th }}$ century the Pashtun, themselves of a complex multi-ethnic background, were divided into two great lineages, the egalitarian Gilzai and the hierarchical Durrani. Eventually the Durrani Pashtun established their hegemonic control over Afghanistan for 230 years. The tensions between these two Pashtun lineages exist to this day (Barfield, 2010: 85-110). Such feudatory tribes, or lineages, come about when neither has a privileged access to resources and compete for the same resource. Within the BMAC conflict would emerge from contested access to the restricted availability of land and water that would, in turn, highlight the importance of conflict, warfare, alliances and demographic patterns.

That the BMAC was characterized by a centralized authority cannot be doubted. The question remains as to whether the BMAC was a centralized singularity or led by a disparity of centralized entities (tribes). Whichever prevailed the function of either would be the same: to organize corvée labor (human capital) for the construction of irrigation works, to maintain central canals, their dams and locks, to collect taxes, and to organize, maintain, provision and control dependent personnel (based on extended families of unfree dependent laborers?) involved in agricultural production. The central authority would also have had judicial responsibilities as well as a monopoly (?) over long distance trade (so abundantly evident in the presence of luxury goods produced of foreign material (gold, silver, lapis lazuli, carnelian, turquoise, tin). The presence of great wealth in the "royal burials" attests to the presence of acquisitive autocrats who secured power by accumulating wealth which in turn under girded their central authority. When thinking of late third millennium Mesopotamia, and the presence of texts, we can, at times, reflect upon the nature of credit institutions, debt, the value of differential products (i.e. onions vs. tin), prebends, sharecropping, judicial punishments, the nature and extent of slavery, even irrigation fees. Within the social world of the BMAC such detail eludes us. However, certain universals within all Bronze Age civilizations, from Egypt to China, may be assumed for the BMAC: slavery, corvée labor, centralized authority within a patrimonial society (Schloen, 2001), the organization of commodity distribution under regional control, the primary role of a central authority in long distance exchange, and a central authorities governance of a distant countryside. Such commonalities, however, are abstractions and offer little understanding as to the specifics of social organization, law, land tenure, or the 'rules' of governance. It is within such specificities that comparisons become meaningful - a trait list of commonalities becomes little more than a laundry list: allegations of similarity without specific meaning or an understanding of difference.

Within the BMAC competition for high quality resources, land and access to water, led to social inequality and the emergence of leadership roles within a pattern of top-down governance. Centralized social control became an instrument of exploitation universally so in all Bronze Age civilizations. This, in turn, resulted in what we may call "social despots", absolute rulers, who used military means to defend their territory, their reproduction, and to acquire ever more high quality resources: land, water and foreign luxury goods. Competition for quality resources, drove social stratification as well as territorial warfare between competing settlement regimes. Irrigation within an arid environment tends to increase the disparity in land quality and increase competition for access to both defensible land and water. Increasing social stratification and the concomitant rise of political elites, within patrimonial lineages, built fortified communities to defend their territorial assets generating further hierarchies, competition, and despotic rule. Within the BMAC (and other agrarian communities) the role of managerial leadership and relations of dominance were coevolutionary phenomenon. The BMAC saw the emergence of an economy based on defensible water and agricultural land (of limited availability), and a skilled labor force, which, on the one hand, was involved in craft production, and, on the other hand, of corvée (attached) laborers involved in agriculture and the construction and maintenance of irrigation networks. One imagines the 
BMAC as a mixed economy (so central to all Bronze Age complexities) in which "private" land ownership was in the hands of groups, i.e. lineages, clans, extended families rather than owned by individuals. Craft production was both "private", individual artisans producing pottery, spinning wool, as well as "public", in the hands of institutions controlled by central authorities producing metals, preciosities, and controlling long distance trade. Karl Polanyi $(1957 ; 1977)$ offered a nuanced approach toward understanding an ancient economy: individual behavior had to be supported by correlated social institutions. Thus, exchange had to be supported by market institutions, redistribution by centralized political structures, and, reciprocity by kinship and acquaintance. He argued that while certain societies could be dominated by one or the other mode it was entirely possible that for a given society all three could be operative. Polanyi's apocalyptic view of his own day and his dislike of capitalist markets led him to draw a sharp and false distinction between the ancient and modern economy. A distinction that led to his belief that markets only typify the modern economy. In fact, all three modes co-exist in the ancient and in the modern economy!

I may seem in this essay to be unduly critical of Victor Sarianidi. That would be an entirely false impression. Once in the Hotel Savoy in Moscow, over an extended lunch, I expressed some of my misgivings about Gonur's stratigraphy, context, chronology, Zoroastrians, etc. I handed to him, for the first time, a series of C-14 dates that he generously allowed us to obtain from Gonur and Togolok (Hiebert, 1993). The carbon dates ranged from $2100-1800$ B.C. At that time Sarianidi was championing a BMAC chronology that he dated to the second half of the second millennium (Sarianidi 1990). After careful scrutiny of the list of dates he handed back the list with the comment, "You have your science, I have mine". In time he was to run his own dates and came to fully accept a BMAC chronology extending from 2200-1700 B.C. Sarianidi is the most generous, affable, and industrious archaeologist it has been my privilege to know. He has been positively prolific in his writing about Gonur, a trait that stands in ready contrast to a significant number of archaeologists who never complete a substantial report on their excavations. Similarly, one may stand opposed to his equally prolific imagination regarding the Zoroastrian world of an Aryan
Gonur. As unlikely as I believe his interpretations are, they stand in stark contrast to the aridity of archaeological reports that chronicle ceramic typologies and analytic charts wholly abandoning the presence of people and social institutions. Sarianidi abjures the aridity of a descriptive, typological, and chronologically staged archaeological science in preference to interpretations and constructed 'meaning'. In a characteristic moment of self awareness, and in response to my criticisms of his excavation strategies, he once told me, and I paraphrase: "I am like Sir Leonard Woolley, I have discovered a civilization and it will take the next generation to work out the details". He is right! Nevertheless, unlike Sir Leonard's reports his will not be an adequate representation of the scientific standards of his day. He offers us a narrative, a montage of temples, palaces, rituals and reconstructed ideologies, all restricted to an uncommon Aryan and Zoroastrian world. His concerns are far removed from landscape, economic subsistence, or the ecologically oriented materialism of processual archaeology, while, perhaps unwittingly, his approach is an exaggerated form of post-processual archaeology, wherein any interpretation makes for as good a 'story' as any other. In the final analysis his is a remarkable achievement...the discovery and elucidation of a rich material culture of a hitherto unknown civilization. It is evident in his many books that Sarianidi is motivated by the recovery of both the aesthetic artifact and the role they play in his uniquely imagined reconstruction of Gonur's social world. As with the study of 'origins', so also with 'discovery', both have an enduring place in the history of archaeology. Victor Sarianidi did not discover the BMAC (Galina Pugachenkova excavated such a site in Margiana in 1949 and I. Masimov, 1975 surveyed the regions of the Murghab in 1972/73) but his decades-long excavations, of what he cumbersomely coined the 'Bactrian Margiana Archaeological Complex', has earned him his place in that history.

Lastly, the discovery of the Oxus Civilization has not been without political import within Turkmenistan. In the last three books written by Victor Sarianidi two Presidents of Turkmenistan, the late Sapamurad Niazov ("Turkmanbashi": Father of the Turks) and presently, Gurganguly Berdimuhamedov, have hailed its discovery as of exceptional importance to the nation state. Turkmanbashi writes in an introduction to 
Sarianidi's (2002) book that it is involved in "pointing out profound historical roots of the Turkman nation (...) [that] ancient Turkmens were bearers of the developed written language and the Turkman land was the fifth center of the world civilization side-by-side with Mesopotamia, Egypt, China and India", while President Gurgbanguly Berdimuhamedov writes: that the BMAC is the first in the world agriculturalists and Sarianidi is to be credited for "producing the fifth centre of the world civilization" (Sarianidi, 2009). There is, of course, not a shred of evidence to suggest that the BMAC was of literate Turkman ethnicity, and a library of evidence against it. There is much irony in the fact that Sarianidi identifies the BMAC with Aryans while the President of the country identifies them as Turkman. In 2001 President Niazov awarded Sarianidi the nation's highest honor, the Makhtumkuli International Prize.

\section{REFERENCES}

ADAMS, R. McC. (1966): Evolution of Urban Societies. Aldine. Chicago.

ADAMS, R. McC. (1986): Heartland of Cities. University of Chicago Press. Chicago.

AMIET, P. (1986): L'age des èchanges inter-iraniens 3500-1700 B.C. avant J.-C. Editions de RMN. Paris.

AMIET, P. (2004): "De l'Élam á la Margiana”, in S. Winkelmann (ed.): Seals of the Oases. Il Punto. Venice.

ANDRIANOV, B.V. (1960): Drevnii Orositel'ny Sistemy Praralya [Ancient Irrigation Systems in the Aral Region]. Nauka. Moscow.

ASKAROV, A.A. and SHIRINOV, T.Sh. (1993): The Early Urban Culture of Bronze Age Southern Uzbekistan. Institute of Archaeology of Uzbekistan. Samarkand.

BAKELS, C.C. (2003): "Report Concerns the Contents of a Ceramic Vessel Found in the White Room of the Gonur Temenos, Merv Oasis, Turkmenistan". Electronic Journal of Vedic Studies. 9 (1C): 3.

BARFIELD, T. (2010): Afghanistan. A Cultural and Political History. Princeton University Press. Princeton.
CATTANI, M. (2008): “The Final Phase of the Bronze Age and the "Andronovo Question in Margiana", in S. Salvatori and M. Tosi (eds.): The Bronze Age and Early Iron Age in the Margiana Lowlands, BAR International Series 1806. Archaeopress. Oxford: 133-148.

CHAZAN, M. (2010): World Prehistory and Archaeology. $2^{\text {nd }}$ edition. Prentice Hall. New York.

CUMMINGS, D. (1977): Country of the Turkmans. Royal Geographical Society. London.

DANI, A.H. and MASSON, V.M. (1992): History of Civilizations of Central Asia. UNESCO Publishing. Paris.

FAGAN, B. (2009): People of the Earth. An Introduction to World Prehistory. $13^{\text {th }}$ edition. Prentice Hall. New York.

FALK, H. (1989): "Soma I and II". Bulletin of the School of Oriental and African Studies, 52 (1): 77-90.

FERNEA, R.A. (1970): Shayk and Effendi. Changing Patterns of Authority Among the El Shabana of Southern Iraq. Harvard University Press. Cambridge, MA.

FRANCFORT, H.-P. and TREMBLAY, J. (2010): "Marhasi et la Civilization de la Oxus". Iranica Antiqua, 45: 512-523.

GUBAEV, A, KOSHELENKO, G. and TOSI, M. (1998): The Archaeological Map of the Murghab Delta. Preliminary Reports. IsIAO. Rome.

HIEBERT, F. (1994): Origins of the Bronze Age Oasis Civilization in Central Asia. America Schoool of Prehistoric Research Bulletin, 42. Harvard University. Cambridge, MA.

HIEBERT, F. and LAMBERG-KARLOVSKY, C.C. (1992): "Central Asia and the Indo-Iranian Borderlands". Iran, 30: 1-17.

HOUBEN, J.E.M. (2003): "The Soma-Haoma Problem". Electronic Journal of Vedic Studies, 9 (1A).

HUNT, R.C. and HUNT, E. (1976): "Canal Organization and Local Social Organization". Current Anthropology, 17 (3): 389-411.

KANUITH, K. (2006): "Metallobjecte der Bronzezeit aus Nordbaktrien". Archäeologie in Iran und Turan, 6. Mainz an Rhein.

KIRCHO, L.; KOROBKOVA, G. and MASSON, V.M. (2008): The Technical and Technological 
Potential of the Eneolithic Population of Altyn Depe as the Basis of an Early Urban Civilization. European House. St. Petersburg.

KLOTCHKOV, I.S. (1998): 'Signs on a Potsherd from Gonur (on the question of the script of Margiana)". Ancient Civilization from Scythia to Siberia, 5 (1): 165-175.

KOHL, P. (1984): Paleolithic Beginnings to the Iron Age. Editions Recherche sur les Civilisations. Paris.

KOHL, P. (2007): The Making of Bronze Age Eurasia. Cambridge University Press. Cambridge.

KOZHIN, P.; KOSAREV, M. and DUBOVA, M. (2010): On the Track of Uncovering a Civilization. Alethia. St. Petersburg.

KUZMINA, E.E. (2007): The Origins of the IndoIranians. Brill. Leiden-Boston.

KUZMINA, E.E. (2008): Arii; put na yug [The Aryans; A Route to the South]. Letnii Sad. Moscow.

LAMBERG-KARLOVSKY， C.C. (1994): "The Bronze Age Khanates of Central Asia". Antiquity, 68 (259): 398-405.

LAMBERG-KARLOVSKY, C.C. (2003): "Civilization, State or Tribe: Bactria and Margiana in the Bronze Age". The Review of Archaeology, 24 (1): 11-20.

LAMBERG-KARLOVSKY, C.C. (2009): "Structure, Agency and Commerce in the Ancient Near East". Iranica Antiqua, 44: 47-88.

LAMBERG-KARLOVSKY, C.C. (2013): "Iran and its Neighbors", in H. Crawford (ed.): The Sumerian World. Routledge. London-New York: 559-579.

LANSDELL, H. (1885): Russian Central Asia including Kuldja, Bokhara, Khiva and Merv. Houghton Mifflin and Co. Boston.

LITSITSINA, G.N. (1965): Oroshayemoye zem ledeliye epokhi eneolita na yuga Turkmenii [Irrigation Agriculture of the Eneolithic Period in Southern Turkmenia]. Nauka. Moscow.

Mac GAHAN, J.A. (1874): Campaigning on the Oxus and the Fall of Khiva. Harper \& Brothers. New York.

MAMEDOV, M. (2003): Drevnii Architectura Bactrii i Margiani [Ancient Architecture of Bactria and Margiana]. Kulturniy Centr Posolistva Islamskoj Iran i Turkmenistana. Ashgabat.
MASIMOV, I. (1975): "New Oasis Settlements of the Bronze Age in the Lower Reaches of the Murghab River". Archaeological Discoveries. Nauka. Moscow: 550-551.

MASSON, V.M. (2001): Peculiarities of manufacture at the Settlement of Altyn depe in the PaleoMetallic Epoch. Materials of the South Turkmenian Interdisciplinary Archaeological Expedition, 5. St. Petersburg.

MCANANY, P. and YOFFEE, N. (2010): Questioning Collapse: Human resilience Ecological Vulnerability and the Aftermath of Empire. Cambridge University Press. Cambridge.

MEADOW, R.H. (1993): Continuity and Change in the Agriculture of the Greater Indus Valley". Information Bulletin, Institute of Oriental Studies, Moscow, 19: 149-163.

MOORE, K.M. (1993): "Animal use in Bronze Age Gonur depe". Information Bulletin, Institute of Oriental Studies, Moscow, 19: 164-176.

MORRIS, I. (2010): Why the West Rules, For Now. Farrar, Straus and Giroux. New York.

MUHAMMEDJANOV, A.R. (1973): Istoria Oroshenija Bukharskogo Oazisa [History of Irrigation in the Bukhara Oasis]. Institute of Archaeology, Uzbek Academy of Sciences. Tashkent.

O'DONOVAN, E. (1882): Merv Oasis. I-II. Smith, Elder and Co. London.

PETRIE, C.A. (ed.) (2013): Ancient Iran and its Neighbors: local developments and long-range interaction in the $4^{\text {th }}$ millennium B.C. (Cambridge, 2008). Oxbow Books. Oxford.

PIANKOVA, L. (1993): "Pottery of Margiana and Bactria in the Bronze Age". Information Bulletin, Institute of Oriental Studies, Moscow, 19: 109127.

POLANYI, K. (1957): "The Economy as Instituted Process", in K. Polanyi, C.M. Arensberg and H.W. Pearson (eds.): Trade and Market in the Early Empires. Basic Books. Glencoe, Il: 240273.

POLANYI, K. (1977): The Livelihood of Man. Academic Press. New York.

POTTS, D. (1999): The Archaeology of Elam. Cambridge University Press. Cambridge. 
POTTS, D. (2008a): "Umm an-Nar Type Compartmented Soft-stone Vessel from Gonur depe, Turkmenistan". Arabian Archaeology and Epigraphy, 19: 168-181.

POTTS, D. (2008b): "Puzur-Inshishinak and the Oxus Civilization (BMAC). Reflections on Shimashki and the Geo-political Landscape of Iran and Central Asia in the Ur III Period". Zeitschrift für Assyriologie, 108: 165-194.

RENFREW, C. and BAHN, P. (2008): Archaeology, Theories, Method, Practice. $5^{\text {th }}$ edition. Thames and Hudson. London.

RATNAGAR, S. (2004): Trading Encounters from the Euphrates to the Indus in the Bronze Age. Oxford University Press. Oxford.

ROSSI OSMIDA, G. (2002): Margiana Gonur-depe Necropolis. Il Punto. Venice.

ROSSI OSMIDA, G. (2008): Adji Kui Oasis, I. La cittadella delle statuette. Il Punto. Venice.

ROSSI OSMIDA, G. (2011): Adji Kui Oasis, II. La cittadella delle statuette. Il Punto. Venice.

SALVATORI, S. (2008a): "Cultural Variability in the Bronze Age Oxus Civilization and its Relations with the Surrounding Regions of Central Asia and Iran" in S. Salvatori and M. Tosi (eds.): The Bronze Age and Early Iron Age in the Margiana Lowlands. BAR International Series 1806. Archaeopress. Oxford: 75-98.

SALVATORI, S. (2008b): “The Margiana Settlement Pattern from the Middle Bronze Age to the Partho-Sasanian Period: A Contribution to the Study of Complexity" in S. Salvatori and M. Tosi (eds.): The Bronze Age and Early Iron Age in the Early Iron Age in the Margiana Lowlands. BAR International Series 1806. Archaeopress. Oxford: $57-74$.

SALVATORI, S. (2010): "Thinking Around Grave 3245 in the "Royal Graveyard" of Gonur", in V. Sarianidi (ed.): On the Track of Uncovering a Civilization. Aletheia. Moscow: 244-257.

SALVATORI, S. and TOSI, M. (eds.) (2008): The Bronze Age and early Iron Age in the Margiana Lowlands. BAR International Series, 1806. Oxford.

SALVATORI, S.; VIDALE, M.; GUIDA, G.; MASIOLI, E. (2009): "Ilgylny (Turkmenistan) and the $4^{\text {th }}$ Millennium B.C. Metallurgy of Central Asia”. Paléorient, 35 (1): 47-67.
SARIANIDI, V. (1960): Eneoliticheskoe poselenie Geoksjur [The Chalcolithic Settlement of Geoksyur Oasis]. Trudy Yuzhno-Turmenskoi Arkheologischeskoi Kompleksnoi Expeditsii, 10. Akademia Nauk. Moscow.

SARIANIDI, V. (1976): Issledovanija pamatnikov Dashlyiskogo Oazisa [Studies of the sites of Dashlin Oasis]. Drevnii Baktria, 1. Akademia Nauk. Moscow.

SARIANIDI, V. (1990): Drevnosti Strani Margush [Antiquities of Margiana]. Akademia Nauk. Ashgabat.

SARIANIDI, V. (1998): Margiana and Protozoroastrianism. Kapon Editions. Athens.

SARIANIDI, V. (2002): Margush. Ancient Oriental Kingdom in the Old Delta of the Murghab River. Türkmendölethabarlary. Ashgabat.

SARIANIDI, V. (2004): Near the Sources of Civilization. UDK. Moscow.

SARIANIDI, V. (2005): Gonur: City of Kings and Gods. Miras. Ashgabat.

SARIANIDI, V. (2007): Necropolis of Gonur. Kapon Editions. Athens.

SARIANIDI, V. (2008a): Zoroastrianism: A New Mother for an Old Religion. Kyriakidis. Athens.

SARIANIDI, V. (2008b): Transactions of the Margiana Archaeological Expedition._Institute of Ethnology and Archaeology. Russian Academy of Sciences. Moscow.

SARIANIDI, V. (2009): Turkmenistan Mystery and True of the Great Culture. Türkmen döwlet nesirgy'at gullugy. Ashgabat.

SARIANIDI, V. (2010): On the Track of Uncovering a Civilization. Aletheia. St. Petersburg

SATAEV, R. (2008): Trudy Margianski arkheologicheskoi ekspeditsii, 2: 138-142.

SCHLOEN, D.J. (2001): The House of the Father as Fact and Symbol. Eisenbrauns. Winona Lake, Wisconsin.

SCARRE, C. (2008): The Human Past: World Prehistory and the Development of the Human Science. $2^{\text {nd }}$ edition. Thames and Hudson. London.

SEARLE, J.R. (2009): Making the Social World. The Structure of Human Civilization. Oxford University Press. Oxford. 
SNEATH, D. (2007): "Headless State" Aristocratic Orders, Kinship Society and Misrepresentation of Nomadic Inner Asia. Columbia University Press. New York.

SCHUYLER, E. (1874): Turkmenistan: Notes on a Journey in Russian Turkistan, Khokand, Bukhara, and Khuldja. I-II. Scribner, Armstrong \& Co. New York.

SOLOVYOVA, N.F. (2005): Chalcolithic Anthropomorphic Figurines from Ilgynly depe. BAR International Series, 1336. Oxford.

STEINKELLER, P. (1982): “The Question of Marhasi: A Contribution to the Historical Geography of Iran in the Third Millennium B.C.". Zeitschrift für Assyriologie, 72: 237-265.

STEINKELLER, P. (2007): "New Light on Shimashki and its Rulers". Zeitschrift für Assyriologie, 97 (2): 215-232.

STEINKELLER, P. (n.d.): "Marhashi and Beyond: The Jiroft Civilization in Historical Perspective", IRAN, 49, 2011 (2014).
SZABO, A. and BARFIELD, T. (1991): An Atlas of Indigenous Domestic Architecture. University of Texas Press. Austin.

TOLSTOV, S.P. (1948): Drevnii Koresmia [Ancient Khorezm]. MGU. Moscow.

UDEUMURADOV, B. (1993): Altyn-Depe I Margiana: Sviazi, Khronologiia, Proikhozhdenie [Altyn depe and Margiana Communication, Chronology, Origins]. Ylym. Ashgabat.

UDEUMURADOV, B. (2002): "Ceramic Materials from Gonur depe Necropolis", in G. RossiOsmida (ed.): Margiana and Gonur depe Necropolis. Il Punto. Venice: 132-144.

VÁMBÉRY, A. (1965): Travels in Central Asia. Harper and Brothers. Philadelphia.

VISICATO, G. (2000): Power and the Writing. The Early Scribes of Mesopotamia. Bethesda. Md.

WINKELMANN, S. (2004): Seals of the Oasis. Il Punto. Venice.

WITTFOGEL, K. (1963): Oriental Despotism: A Comparative Study of Total Power. Yale University Press. New Haven. 
